\title{
HDAC6-selective inhibitor synergistically enhances the anticancer activity of immunomodulatory drugs in multiple myeloma
}

\author{
HYE-RIM WON ${ }^{1}$, DONG HOON LEE ${ }^{1,2}$, SOO-KEUN YEON ${ }^{1}$, \\ HYUN-WOOK RYU ${ }^{1}$, GO WOON KIM ${ }^{1}$ and SO HEE KWON ${ }^{1,2}$ \\ ${ }^{1}$ College of Pharmacy, Yonsei Institute of Pharmaceutical Sciences, Yonsei University, Incheon 21983; \\ ${ }^{2}$ Department of Integrated OMICS for Biomedical Science, Yonsei University, Seoul 03722, Republic of Korea
}

Received October 1, 2018; Accepted June 3, 2019

DOI: $10.3892 /$ ijo.2019.4828

\begin{abstract}
Nonselective histone deacetylase (HDAC) inhibitors have therapeutic effects, but exhibit dose-limiting toxicities in patients with multiple myeloma (MM). The present study investigated the interaction between the HDAC6 inhibitor, A452, and immunomodulatory drugs (IMiDs) on dexamethasone (Dex)-sensitive and -resistant MM cells compared with the current clinically tested HDAC6 inhibitor, ACY-1215. It was shown that the combination of the HDAC6-selective inhibitor, A452, with either of the IMiDs tested (lenalidomide or pomalidomide) led to the synergistic inhibition of cell growth, a decrease in the viability of MM cells and in an increase in the levels of apoptosis. Furthermore, enhanced cell death was associated with the inactivation of AKT and extracellular signal-regulated kinase (ERK)1/2. Of note, A452 in combination with IMiDs induced synergistic MM cytotoxicity without altering the expression of cereblon and thereby, the synergistic downregulation of IKAROS family zinc finger (IKZF) $1 / 3$, c-Myc and interferon regulatory factor 4 (IRF4). Furthermore, combined treatment with A452 and IMiDs induced the synergistic upregulation of PD-L1. More importantly, this combination treatment was effective in the Dex-resistant MM cells. Overall, the findings of this study
\end{abstract}

Correspondence to: Professor So Hee Kwon, College of Pharmacy, Yonsei Institute of Pharmaceutical Sciences, Yonsei University, 85 Songdogwahak-ro, Yeonsu-gu, Incheon 21983, Republic of Korea E-mail: soheekwon@yonsei.ac.kr

Abbreviations: BTZ, bortezomib; Bcl-xL, B-cell lymphoma-extra large protein; CRBN, cereblon; CI, combination index; DEX, dexamethasone; ERK, extracellular signal-regulated kinase; $\mathrm{F}_{\mathrm{A}}$, Fraction affected; HDAC, histone deacetylase; HDACi, histone deacetylase inhibitor; $\gamma \mathrm{H} 2 \mathrm{AX}$, phosphorylated H2AX; IMiD, immunomodulatory drugs; IRF4, interferon regulatory factor 4; Len, lenalidomide; MM, multiple myeloma; PARP, poly(ADP ribose) polymerase; Pom, pomalidomide; SAHA, suberoylanilide hydroxamic acid

Key words: HDAC6, HDAC6-selective inhibitor, immunomodulatory drug, multiple myeloma, combination therapy indicate that $\mathrm{A} 452$ is more effective as an anticancer agent than ACY-1215. Taken together, these findings suggest that a combination of the HDAC6-selective inhibitor, A452, and IMiDs may prove to be beneficial in the treatment of patients with MM.

\section{Introduction}

Multiple myeloma (MM) is the second most frequent hematological malignancy and represents $1 \%$ of all types of types of cancer. MM is a malignant hematological disorder characterized by the accumulation of abnormal plasma cells in the bone marrow, the secretion of monoclonal immunoglobulin (Ig) into the serum and urine, and the absence of IgM expression. Symptomatic MM exhibits characteristics, such as hypercalcemia, renal failure, osteopenic or osteolytic bone disease and anemia; however, patients with MM may be diagnosed at an asymptomatic stage by chance (1). The pathogenesis of MM is characterized by the progressive acquisition of genetic lesions, such as translocations, deletions and mutations in the regulating genes of plasma cells, promoting, in the early stage, binding with bone marrow stromal cells. Nuclear factor (NF)- $\kappa B$ is activated by the mutations that occur during the progression of MM. It upregulates cell surface adhesion molecules and increases growth, anti-apoptotic and angiogenic cytokine production, including interleukin (IL)-6, tumor necrosis factor- $\alpha$, insulin-like growth factor-1 and vascular endothelial growth factor (VEGF), in addition to the secretion of IL-10 and transforming growth factor- $\beta$ secretion by tumor plasma cells, leading to the dysregulation of B- and T-cells immune surveillance. This whole process supports the survival, proliferation and chemoresistance of tumor plasma cells $(2,3)$.

Despite recent improvements in treatment leading to significantly increased overall survival rates, the majority of patients with MM have a differential level of residual disease, leading to cyclic relapse and finally, to refractory disease (4). Following disease relapse, the main therapies are predominantly old classes of drugs, including corticosteroids [e.g., prednisone and dexamethasone (Dex)] used individually, and novel active classes of drugs, including proteasome inhibitors [bortezomib (BTZ) and carfilzomib] and immunomodulatory drugs (IMiDs), in combination with each other or in combination with other less active agents $(5,6)$. 
The IMiD class of drugs, including lenalidomide (Len) and pomalidomide (Pom), exhibit potent anti-myeloma properties in various MM models, and have shown significant clinical activity in patients with MM. Len is a 4-aminoglutarimide derivative of thalidomide, which possesses markedly fewer neurologic toxic effects associated with thalidomide (7). It has pro-apoptotic and antiproliferative effects, boosts antitumor immunity via T-cell proliferation, IL-2 and interferon- $\gamma$ production and the activation of cell adhesion molecules, and promotes antiangiogenic activity by reducing VEGF and fibroblast growth factor (FGF) production by the endothelium and bone marrow stroma (7-11). Recent studies have demonstrated that thalidomide and other IMiDs directly bind cereblon (CRBN), an E3 ubiquitin ligase that controls the ubiquitination and degradation of IKAROS family zinc finger (IKZF)1 (known as Ikaros) and IKZF3 (known as Aiolos) (12-14). The reduced expression of IKZF1/IKZF3 leads to decreased levels of NF- $\kappa \mathrm{B}, \mathrm{c}-\mathrm{Myc}$ and interferon regulatory factor 4 (IRF4), which play a pivotal role in the pathogenesis of $\mathrm{MM}$, and the increased expression of $\mathrm{p} 21$, resulting in anti-MM activity in a CRBN- and p21-dependent, but p53-indendent manner (15). Similar to thalidomide and Len, Pom exerts its antitumor activity by direct antiproliferative and pro-apoptotic effects on plasma cells, by immunomodulation, and by the modulation of the bone marrow microenvironment. Importantly, Pom has been shown to be more active than the two previously mentioned IMiDs (16).

HDAC inhibitors (HDACis) have emerged as promising agents for the treatment of MM and other tumor types (17-19). HDACis kill cells through multiple mechanisms (20). Two pan-HDACis, suberoylanilide hydroxamic acid (SAHA or vorinostat) and romidepsin, have been approved by the US Food and Drug Administration for the treatment of cutaneous T cell lymphoma (21-23). Previous studies have shown the potential clinical activity of a combination of the non-selective HDACi, SAHA (24), or LBH589 (panobinostat) (25) and Dex with Len or BTZ (26) in patients with MM. Recently, panobinostat was approved as a combination drug regimen (BTZ + Dex) for the treatment of MM; however, it exhibits serious toxicities that limits its clinical utility (27). Therefore, more tolerable HDAC inhibitors are required. As MM cells are sensitive to HDAC6 inhibition, HDAC6-selective inhibitors are attractive candidates for MM treatment. HDAC6-selective inhibitors target the aggresome and proteasome protein degradation pathways without substantially altering gene expression and may thus have an improved safety profile compared with pan-HDACis. Several HDAC6-selective inhibitors have been previously reported (28-32). ACY-1215 (ricolinostat) is the only first-in-class clinically relevant HDAC6i with minimal effects on class I HDACs $(31,33)$. Combination treatment with ricolinostat and Dex with Len (34) or BTZ (35) is under clinical assessment in relapsed/ refractory (R/R) MM. Therefore, there is a need for the further development of HDAC6-selective inhibitors that do not produce side-effects, such as diarrhea, fatigue, nausea, vomiting, neutropenia and thrombocytopenia, due to non-selective class I HDAC inhibition.

In our recent study, we developed an HDAC6-selective inhibitor A452 (36), which also exerts significant cell growth inhibition and decreases cell viability in various cancer cells (37) and in vivo murine xenograft colon cancer model (36). Therefore, the present study aimed to examine whether the novel HDAC6-selective HDACi, A452, together with IMiDs induces synergistic anti-MM activity, in order to provide the rationale for combination clinical trials. The present study also investigated whether A452 in combination with IMiD overcomes drug resistance in MM.

\section{Materials and methods}

Cells and cell culture. The Dex-sensitive, MM.1S (CRL-2974), and Dex-resistant, H929 (CRL-9068), MM cell lines and bone marrow derived mesenchymal stromal cells (BM-MSCs; PCS-500-012) were purchased from the American Type Culture Collection (ATCC). The cells were cultured in medium (HyClone; GE Healthcare Life Sciences) containing 10\% fetal bovine serum (HyClone; GE Healthcare Life Sciences), $100 \mathrm{U} / \mathrm{ml}$ penicillin and $100 \mu \mathrm{g} / \mathrm{ml}$ streptomycin (Gibco; Thermo Fisher Scientific, Inc.) in a humidified atmosphere of $5 \% \mathrm{CO}_{2}$ and $95 \%$ air at $37^{\circ} \mathrm{C}$.

Reagents. SAHA and Dex were purchased from Sigma-Aldrich (Merck KGaA). Bortezomib, Len, Pom, and ACY-1215 were purchased from Selleck Chemicals. A452 (purity 99\%) is a $\gamma$-lactam based HDAC6 inhibitor (36) and was kindly provided by Dr Gyoonhee Han (Yonsei University).

Cell growth and viability assay. Each cell culture of MM cells was performed in triplicate, and cell growth and viability were determined using Cell Counting kit (CCK)-8 kit assays (Dojindo Molecular Technologies, Inc.) according to the manufacturer's protocol, as described previously (38).

Inhibitory assays. Drug concentrations that inhibited 50\% of cell growth $\left(\mathrm{GI}_{50}\right)$ and $50 \%$ of cell viability $\left(\mathrm{IC}_{50}\right)$ were determined using a CCK-8 assay. All cell lines were treated for $72 \mathrm{~h}$ on day 2, unless otherwise stated. $\mathrm{GI}_{50}$ and $\mathrm{IC}_{50}$ were determined using Prism Version 6.0 software (GraphPad Software, Inc.).

Short hairpin RNA (shRNA) infection and generation of stable knockdown cell lines. The lentiviral shRNA sets for HDAC6 were purchased from Sigma-Aldrich; Merck KGaA. The following sequences within human HDAC6 were targeted: CCGGCATCCCATCCTGAATATCCTTCTCGAGAAGGAT ATTCAGGATGGGATGTTTTTG(\#1,NM_006044.2-3840s1c1 TRCN0000314976) and CCGGCCTCACTGATCAGGCC ATATTCTCGAGAATATGGCCTGATCAGTGAGGTTTTT (\#2, NM_006044.2-2049s1c1, TRCN0000004843). The non-targeted shRNA sequence was CCGGGCGCGATAGCG CTAATAATTTCTCGAGAAATTATTAGCGCTATCGCGC TTTTT (SHC016; Sigma-Aldrich). To generate respective lentivirus, 293T cells (CRL-11268; ATCC) were co-transfected with the shRNA vector and necessary packaging plasmids. Supernatants containing lentivirus were collected 48 and $72 \mathrm{~h}$ after transfection and passed through a $0.45-\mu \mathrm{m}$ filter. The cells were then infected 3 times (every $12 \mathrm{~h}$ ) with the lentivirus in the presence of hexadimethrine bromide. Subsequently, cells were selected for 2 days in $2 \mu \mathrm{g} / \mathrm{ml}$ puromycin, as the pLKO.1 vector encodes the respective antibiotic resistance gene. 
Western blot analysis. The treated cells were collected and lysed with NP-40 lysis buffer [0.5\% NP-40, $50 \mathrm{mM}$ Tris- $\mathrm{HCl}$ (pH 7.4), $120 \mathrm{mM} \mathrm{NaCl}, 25 \mathrm{mM} \mathrm{NaF}, 25 \mathrm{mM}$ glycerol phosphate, $1 \mathrm{mM}$ EDTA, $5 \mathrm{mM}$ EGTA, $1 \mathrm{mM}$ PMSF and $1 \mathrm{mM}$ bezamidine]. The protein concentration was measured using a bicinchoninic acid kit (Pierce; Thermo Fisher Scientific, Inc.). Cell lysates containing 50-80 $\mu \mathrm{g}$ total protein were subjected to $8-15 \%$ by sodium dodecyl sulfate-polyacrylamide gel electrophoresis (SDS-PAGE). Western blot analysis was performed as described previously (38). The nictrocellulose membranes were blocked for $1 \mathrm{~h}$ in PBS containing 0.1\% Tween-20 and $10 \%$ (v/v) skim milk (Bio-Rad Laboratories, Inc.) and incubated overnight at $4^{\circ} \mathrm{C}$ with primary antibodies (1:500-1:2,000). The following primary antibodies were used. Acetylated- $\alpha$-tubulin (DM1A, T6793-2ML; 1:2,000) was purchased from Sigma-Aldrich (Merck KGaA). Protein kinase B (AKT; H-136, sc-8312; 1:1,000), phosphorylated (p)-AKT (Ser473, sc-7985; 1:500), B-cell lymphoma (Bcl)-2 homologous antagonist/killer (Bak; G-23, sc-832; 1:1,000), extracellular signal-regulated kinase (ERK; K-23, sc-94; 1:1,000), HDAC6 (H-300, sc-11420; 1:1,000), IRF4 (M-17, sc-6059, 1:2000), c-Myc (9E10, sc-40, 1:500), p38 (C-20, sc-535, 1:1,000), and $\alpha$-tubulin (sc-32293; 1:2,000) were obtained from Santa Cruz Biotechnology, Inc. Anti-HIF-1 $\alpha$ (610958, 1:500), poly (ADP-ribose) polymerase (PARP; 551024; 1:1,000), and XIAP (10716, 1:1000) antibodies was purchased from BD Biosciences. Bax (2772, 1:500), Bcl-2 (2870, 1:500), B-cell lymphoma-extra large protein (Bcl-xL; $2762 ; 1: 500)$, caspase-3 (9662S; 1:1,000), caspase-8 (9746, 1:500), caspase-9 (9508, 1:500), p-ERK (Thr202/Tyr204; $4376 ; 1: 1,000)$, GAPDH (14C10, 2118, 1:1,000), IKZF1 (5443, 1:500), IKZF3 (12720, 1:500), signal transducer and activator of transcription 3 (STAT3; 12640; 1:1,000), p-STAT3 (Y705, 9138; 1:500), and phospho-p38 (Thr180/Tyr182; 9211, 1:500) were obtained from Cell Signaling Technology, Inc. Acetylated-histone H3 (06-599, 1:1,000) and histone H3 (06-755; 1:500) antibodies were obtained from EMD Millipore. Anti-CRBN antibody (ARP56882-P050, 1:1,000) was purchased from Aviva Systems Biology. Anti-programmed death-ligand 1 (PD-L1) antibody (PA5-28115; 1:1,000) was purchased from Invitrogen; Thermo Fisher Scientific, Inc. The membranes were then washed with $0.1 \%$ Tween-20/PBS and incubated at room temperature for $1 \mathrm{~h}$ with horseradish peroxidase-conjugated anti-rabbit (111-035-003; 1:5,000) and anti-mouse (115-035-003; 1:10,000) secondary antibodies (Jackson ImmunoResearch Laboratories, Inc.). The bound antibodies were detected using an enhanced chemiluminescence western blotting analysis system (NCI4080KR, Thermo Fisher Scientific, Inc.) and the blots were semi-quantified using FusionCapt software version 16.08a (Viber Lourmat Sté, Collégien).

Acid extraction of histones. The acid extraction of histones from the MM cells was performed as previously described (38).

Apoptosis assay. Apoptosis was assessed using Annexin V/ propidium iodide (PI) double staining, according to the manufacturer's protocol (BD Biosciences). Following treatments, the cells were stained with $0.5 \mathrm{mg} / \mathrm{ml}$ Annexin $\mathrm{V}$ in binding buffer (10 mM HEPES free acid, $0.14 \mathrm{M} \mathrm{NaCl}$, and $2.5 \mathrm{mM}$ $\mathrm{CaCl}_{2}$ ) for $30 \mathrm{~min}$ at room temperature. Subsequently, PI
(5 $\mathrm{mg} / \mathrm{ml}$ final concentration) was added, and the cells were incubated for a further $15 \mathrm{~min}$ at room temperature. The cells were then analyzed using a flow cytometer and BD FACSDiva software version 7 (both from BD Biosciences).

Drug combination analysis. For combined drug analysis, a constant ratio combination of A452 and other compounds was evaluated. Drug dilutions and combinations were prepared in medium immediately before use. Cells $\left(2 \times 10^{4} /\right.$ well) in 96-well plates were incubated with the drugs for $72 \mathrm{~h}$ at $37^{\circ} \mathrm{C}$. A CCK-8 assay was performed to determine cell viability. Drug interactions were determined according to the combination index (CI) method described by Chou (39); CI $>1$ implies antagonism, $\mathrm{CI}=1$ is additive and $\mathrm{CI}<1$ implies synergism. CIs for the combination treatment groups were generated using CalcuSyn software version 2.11 (Biosoft). The fraction affected $\left(\mathrm{F}_{\mathrm{A}}\right)$ was calculated from the percent viability, as follows: $\mathrm{F}_{\mathrm{A}}=(100$ - percentage viability $) / 100$.

Statistical analysis. Statistical analyses were performed using GraphPad Prism software version 5.01 (Version 5.0, Graphpad Software Inc.). All data are presented as the means \pm standard deviation from 3 independent experiments. Statistical significance was determined by one-way analysis of variance with post hoc analysis using Tukey's multiple comparison test. $\mathrm{P}<0.05$ was considered to indicate a statistically significant difference.

\section{Results}

A452 selectively inhibits HDAC6 in MM. We, as well as others have previously reported that A452 is a specific HDAC6 inhibitor in solid tumors $(36,37)$. To confirm the specific HDAC6 inhibitory effect of A452 in MM, its effects on the acetylation of $\alpha$-tubulin and histone H3 were examined. The MM.1S and H929 cells were treated with increasing concentrations of A452 for $24 \mathrm{~h}$. A dose-dependent increase in acetylated $\alpha$-tubulin was observed following treatment with low concentrations $(0.05 \mu \mathrm{M})$ of $\mathrm{A} 452$, without affecting histone acetylation $(<0.5 \mu \mathrm{M})$, in the MM.1S cells, confirming its more selective inhibitory effect on HDAC6 activity (Fig. 1A). To determine the selectivity of A452 for HDAC6 over class I HDACs, the concentration required to increase acetylated levels of $\alpha$-tubulin was compared with that required to increase acetylated levels of histone H3. The levels of acetylated- $\alpha$-tubulin and acetylated-H3 were semi-quantified relative to $\alpha$-tubulin and histone $\mathrm{H} 3$, respectively, and a $>2$-fold increase in the acetylated levels was considered to indicate a significant inhibitory effect. Based on the results of western blot analysis, A452 was $~ 10$-fold (HDAC6 inhibitory concentration, $0.05 \mu \mathrm{M}$; vs. class I HDAC inhibitory concentration, $0.5 \mu \mathrm{M}$ ) and 500 -fold (0.001 vs. $0.5 \mu \mathrm{M})$ less active against class I HDACs in the MM.1S and H929 cells, respectively (Figs. 1A and $\mathrm{B}$ and S1). The pan-HDAC inhibitor, SAHA, was used as a positive control for HDAC inhibition (40). These results indicated that A452 may be an HDAC6-selective inhibitor with minimal class I HDAC activity in MM cells.

A452 induces time- and does-dependent cytotoxicity in MM cells. The effects of A452 on cell growth and viability 
A
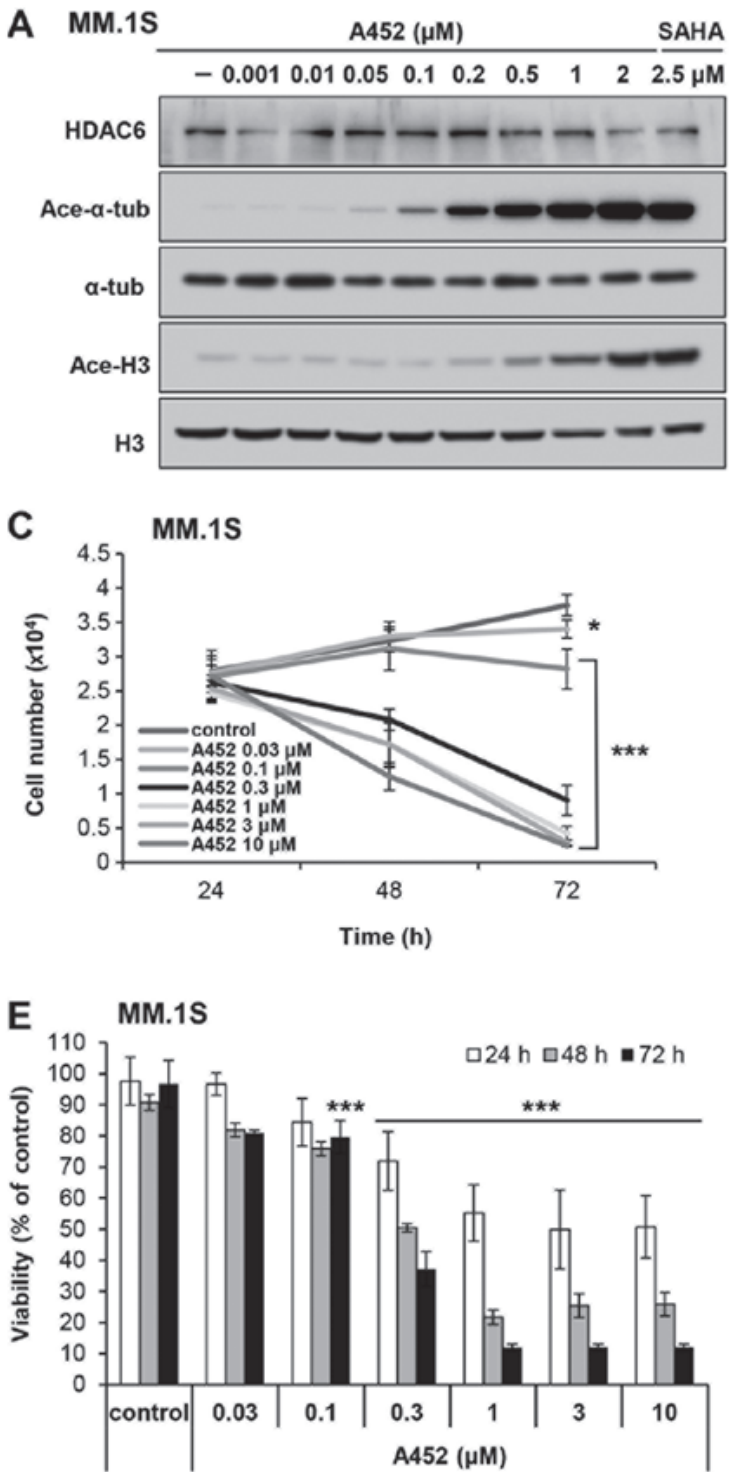

B $\mathrm{H} 929$

A452 $(\mu \mathrm{M})$

SAHA

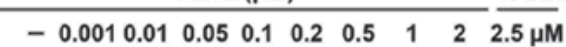

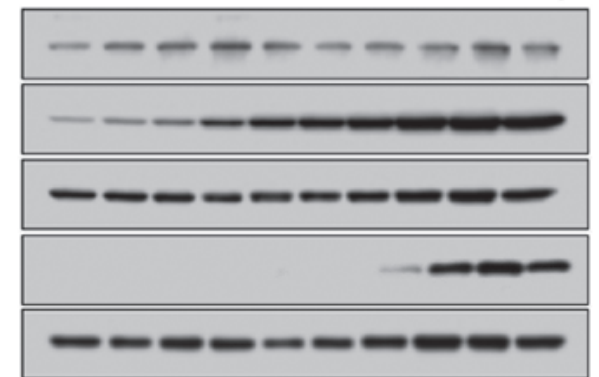

D

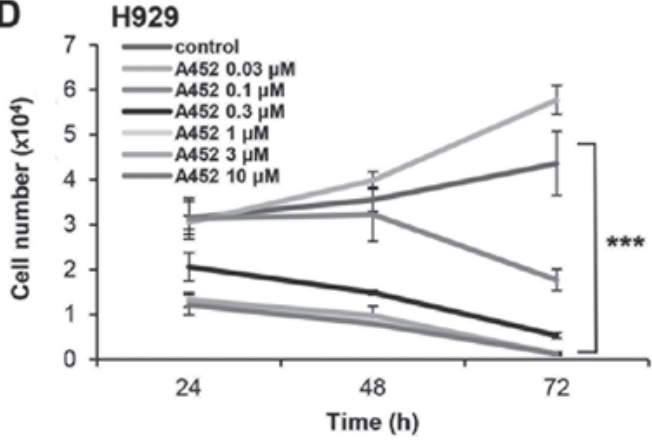

$\mathbf{F}$

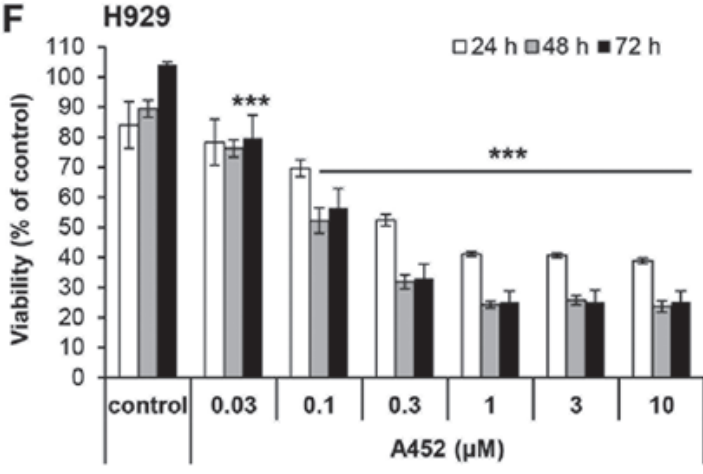

Figure 1. A452, an HDAC6-selective inhibitor, suppresses the growth and viability of MM cells. (A) MM.1S and (B) H929 cells were treated with A452 at the indicated concentrations $(0.001,0.01,0.05,0.1,0.2,0.5,1$ and $2 \mu \mathrm{M})$ for $24 \mathrm{~h}$ and western blot analysis was performed with antibodies against acetylated $\alpha$-tubulin (Ace- $\alpha$-tub), acetylated histone $\mathrm{H} 3$ (Ace-H3) and $\alpha$-tubulin ( $\alpha$-tub) and total histone H3 (H3). $\alpha$-tubulin and histone H3 are shown as equal loading controls. The pan-HDAC inhibitor, SAHA $(2.5 \mu \mathrm{M})$, was used as a positive control for HDAC inhibition. Growth and viability of (C and E) MM.1S and (D and F) H929 cells cultured with 0.1\% DMSO (control) or A452 at indicated concentrations $(0.03,0.1,0.3,1,3$ and $10 \mu \mathrm{M})$ for $72 \mathrm{~h}$. Viable cell numbers and viability were measured using CCK-8 assays. Cell counts were estimated indirectly from a standard curve generated using solutions of known cell counts. Absorbance was normalized to that of the negative control at each time interval. Data are expressed as the means \pm standard deviation from 3 independent experiments. ${ }^{*} \mathrm{P}<0.05$ and ${ }^{* * * *} \mathrm{P}<0.001$, vs. the DMSO control (analysis of variance). HDAC, histone deacetylase.

were examined in the MM.1S and H929 MM cells. The cells were treated with A452 for up to $72 \mathrm{~h}$, and cell growth and viability were measured using CCK-8 assays. In addition, to determine whether A452 can overcome resistance to Dex, Dex-resistant H929 cells and Dex-sensitive MM.1S cells were used. Compared with the control cells, A452 (except at the dose of $0.03 \mu \mathrm{M}$ ) resulted in a time- and dose-dependent decrease in the growth and viability of both $\mathrm{MM}$ cells, with $\mathrm{GI}_{50}$ and $\mathrm{IC}_{50}$ values of $0.24-0.69 \mu \mathrm{M}$ and $0.17-0.44 \mu \mathrm{M}$, respectively (Fig. 1C-F). In addition, the inhibitory effect of A452 on the growth (1.3-1.5-fold) and viability (2.1-2.6-fold) of the MM cells was greater than that of ACY-1215 (Table I). By contrast, at the concentration of $\leq 1 \mu \mathrm{M}, \mathrm{A} 452$ and ACY-1215 did not alter the total number of viable BM-MSCs, whereas only higher concentrations $(\sim 2 \mu \mathrm{M})$ inhibited cell viability (data not shown). In particular, A452 and ACY-1215 exhibited significant anti-proliferative activity in the Dex-resistant H929 MM cell line, suggesting the ability of A452 and ACY-1215 to overcome Dex resistance. Taken together, these findings suggest that the selective inhibition of HDAC6 by A452 induces cell death and overcomes drug resistance in MM.

A452 in combination with IMiDs exerts synergistic cytotoxic effects. The combined effect of IMiDs and an HDAC6-selective inhibitor on MM cytotoxicity was then assessed. The MM.1S and H929 MM cells were treated with either A452 alone, or in combination with Len and Pom, and a CCK-8 assay was performed to measure cell growth and viability for $72 \mathrm{~h}$. This combined treatment resulted in synergistic growth inhibitory effect on both cell lines (Fig. 2A and D). A substantial decrease 

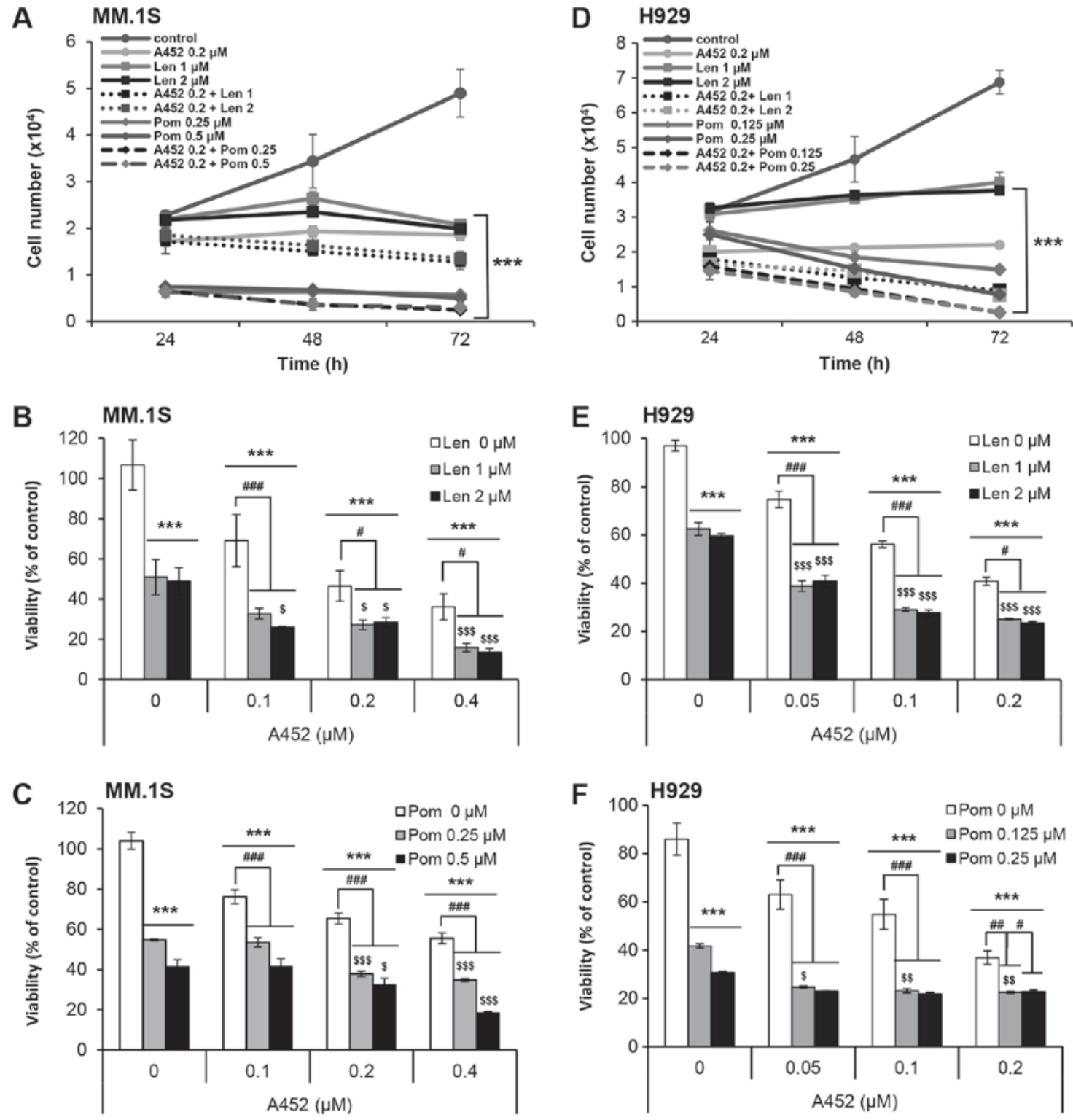

Figure 2. Co-treatment with IMiD and A452 triggers synergistic cytotoxicity. (A-C) MM.1S and (D-F) H929 cells were treated with $0.1 \%$ DMSO (control), A452 (0.05-0.4 $\mu \mathrm{M})$, Len $(1,2 \mu \mathrm{M})$ or Pom $(0.125-0.5 \mu \mathrm{M})$ or in combination with these compounds as indicated for $72 \mathrm{~h}$. Cell growth and viability were measured using CCK-8 assays. Combination treatments were then performed in (A-C) MM.1S and (D-F) H929 cells maintaining a constant ratio between the dose of the A452 and IMiDs. Cell growth (24-72 h) and viability ( $72 \mathrm{~h}$ ) were measured using CCK-8 assays. Cell counts were indirectly estimated from a standard curve generated using solutions of known cell counts. Absorbance was normalized to that of the negative control at each time interval. Data are expressed as the means \pm standard deviation from 3 independent experiments. ${ }^{* * * *} \mathrm{P}<0.001$, vs. the DMSO control; ${ }^{\#} \mathrm{P}<0.05,{ }^{\# \#} \mathrm{P}<0.01$ and ${ }^{\# \# "} \mathrm{P}<0.001$, vs. the A452-treated group; ${ }^{\$} \mathrm{P}<0.05,{ }^{\$ \$} \mathrm{P}<0.01$ and ${ }^{\$ \$ \$} \mathrm{P}<0.001$, vs. the Len or Pom-treated group (analysis of variance). IMiDs, immunomodulatory drugs; Len, lenalidomide; Pom, pomalidomide.

Table I. Growth and viability inhibitory effects of A452 and ACY-1215 in MM cell lines.

\begin{tabular}{lcccccc}
\hline \multirow{2}{*}{ Cell line } & & Time (h) & \multicolumn{2}{c}{$\mathrm{A} 452(\mu \mathrm{M})$} & & \multicolumn{2}{c}{$\mathrm{ACY}-1215(\mu \mathrm{M})$} \\
& $\mathrm{GI}_{50}$ & $\mathrm{IC}_{50}$ & & $\mathrm{GI}_{50}$ & $\mathrm{IC}_{50}$ \\
\hline MM.1S & 48 & 0.688 & 0.435 & & 0.875 & 1.137 \\
& 72 & 0.139 & 0.159 & & 0.817 & 1.148 \\
H929 & 48 & 0.243 & 0.174 & & 0.371 & 0.369 \\
& 72 & 0.047 & 0.196 & & 0.424 & 0.435 \\
\hline
\end{tabular}

$\mathrm{GI}_{50}$, drug concentration that inhibited $50 \%$ of cell growth; $\mathrm{IC}_{50}$, drug concentration that inhibited $50 \%$ of cell viability. in viability was observed following combined treatment compared with a single agent. Synergism was evaluated by using the Chou-Talalay method (39). The combination of A452 and Len or Pom exhibited synergistic anti-MM activity with a combination index of $<1.0$ (Fig. 2B, C, E and F, and Table II). Similarly, the combination of ACY-1215 and IMiDs exerted synergistic cytotoxic effects (Table II) These data confirmed the robust anti-proliferative effect when A452 and IMiD were used in combination in Dex-sensitive and Dex-resistant MM cells.

A452 in combination IMiDs synergistically induces apoptosis. To investigate the mechanisms of the synergistic cytotoxicity induced by the combination treatment, the activation of apoptotic pathways was evaluated by Annexin V/PI staining. 
A MM.1S

- Dead uLate apoptosis $\square$ Early apoptosis $\square$ Live

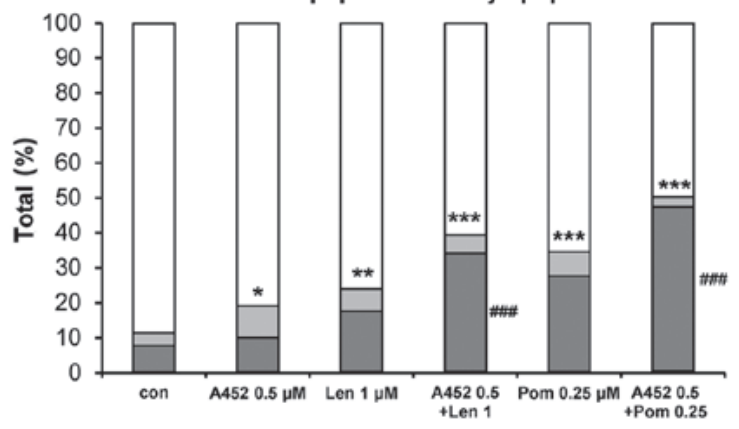

C

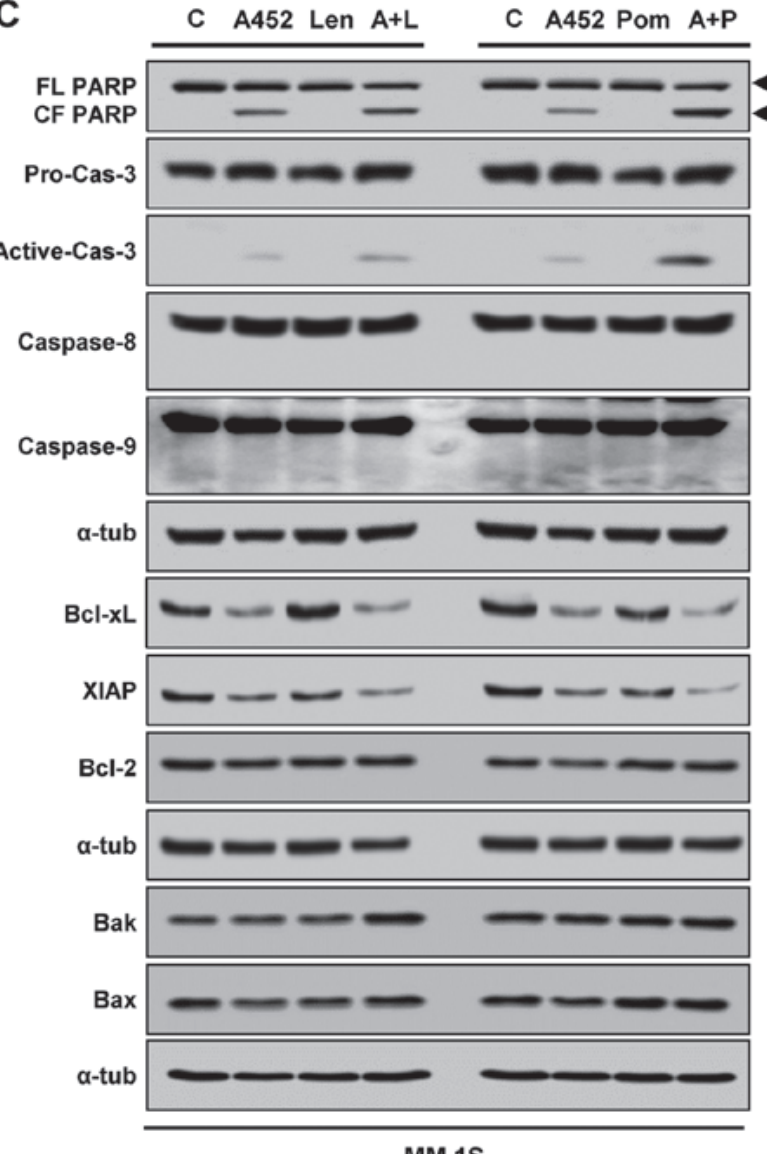

B $\quad$ H929

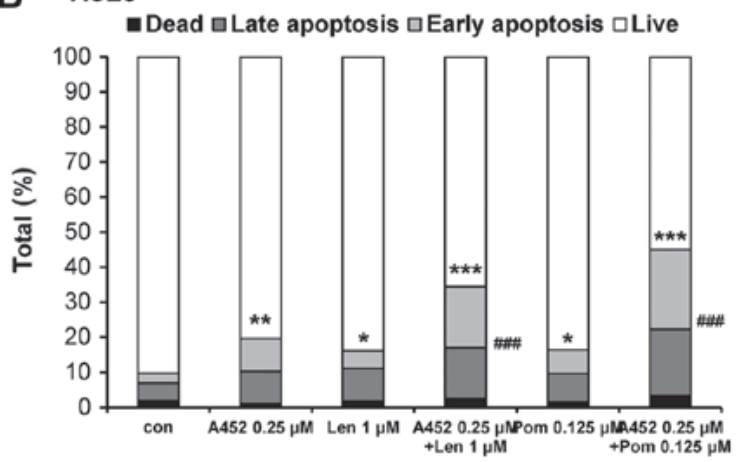

D

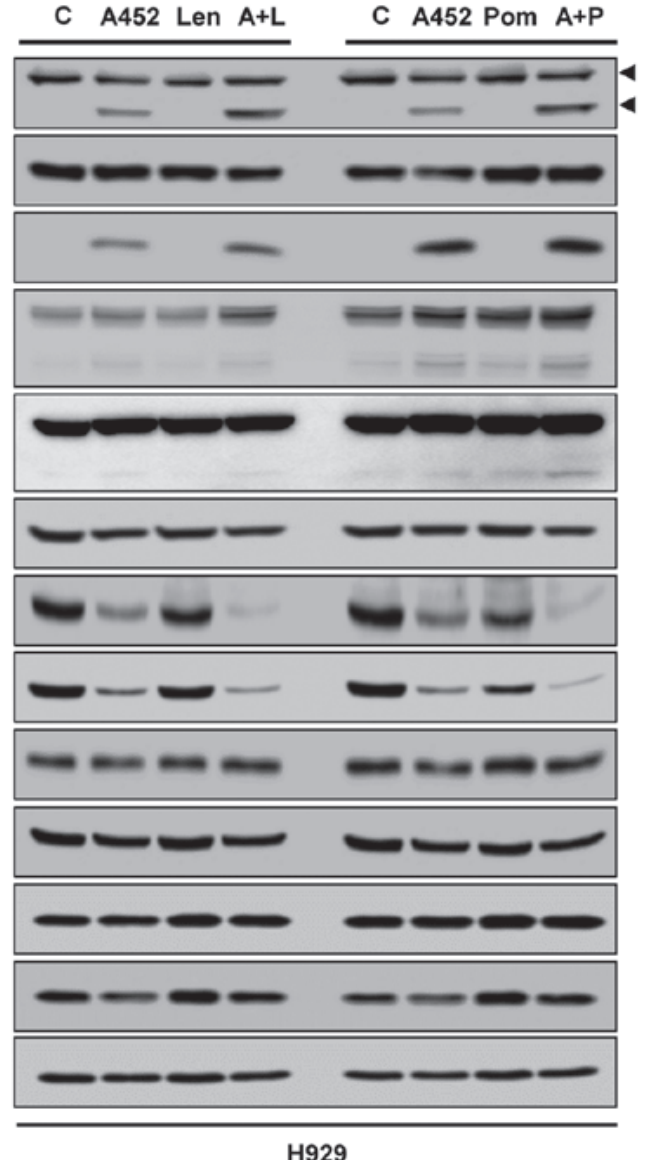

Figure 3. Co-treatment with IMiD and A452 leads to synergistic apoptosis induction. (A) MM.1S and (B) H929 cells were treated with 0.1\% DMSO (control), A452 $(0.25$ and $0.5 \mu \mathrm{M})$, Len $(1 \mu \mathrm{M})$ or Pom $(0.125$ and $0.25 \mu \mathrm{M})$ or in combination with these compounds, as indicated, for 5 days and stained with Annexin V and propidium iodide for $45 \mathrm{~min}$. Apoptosis induced by these compounds was assessed by flow cytometry $(\mathrm{n}=3)$. Data are expressed as the means \pm standard deviation from 3 independent experiments. ${ }^{*} \mathrm{P}<0.05,{ }^{* * *} \mathrm{P}<0.01$ and ${ }^{* * *} \mathrm{P}<0.001$, vs. apoptotic cells in the DMSO control; ${ }^{\# \# \#} \mathrm{P}<0.001$, vs. apoptotic cells in A452-treated group (analysis of variance). (C) MM.1S and (D) H929 cells were treated with $0.1 \%$ DMSO (control), A452 (0.5 $\mu \mathrm{M})$, Len (1 $\mu \mathrm{M})$ or Pom $(0.25 \mu \mathrm{M})$ or in combination with these compounds, as indicated, for $24 \mathrm{~h}$. Whole-cell lysates were subjected to immunoblotting with indicated antibodies. $\alpha$-tubulin was used as a loading control. IMiDs, immunomodulatory drugs; Len, lenalidomide; Pom, pomalidomide.

The population of Annexin V-positive cells following treatment with A452, Len or Pom was 18.9, 23.6 and $34.3 \%$ in the MM.1S cells and 18.4, 14.4 and $14.8 \%$ in the H929 cells, respectively, which increased to 39 and $49.7 \%$ in the MM.1S, and 31.9 and $41.6 \%$ in the H929 cells, respectively, following combination treatment (Figs. 3A and B, and S2). To examine the molecular mechanisms of apoptosis, western blot analysis was performed. Combination treatment markedly downregulated the levels of the Bcl-xL and XIAP anti-apoptotic proteins without altering the levels of Bcl-2 anti-apoptotic protein, and
Bax and Bak pro-apoptotic proteins. Combination treatment triggered the synergistic cleavage of caspase- 3 and PARP (Figs. 3C and D, and S3). However, combination treatment caused the cleavage of caspase- 8 and caspase- 9 in the H929 cells, but not the MM.1S cells. In addition, combination treatment with ACY-1215 and IMiDs triggered apoptosis (data not shown). However, ACY-1215 was less effective than A452. Overall, these results indicated that A452 and Len or Pom induced apoptosis by activating caspases and downregulating anti-apoptotic factors. 
A

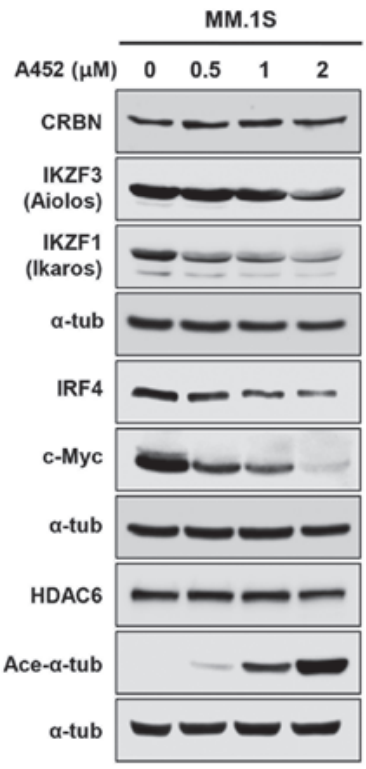

C

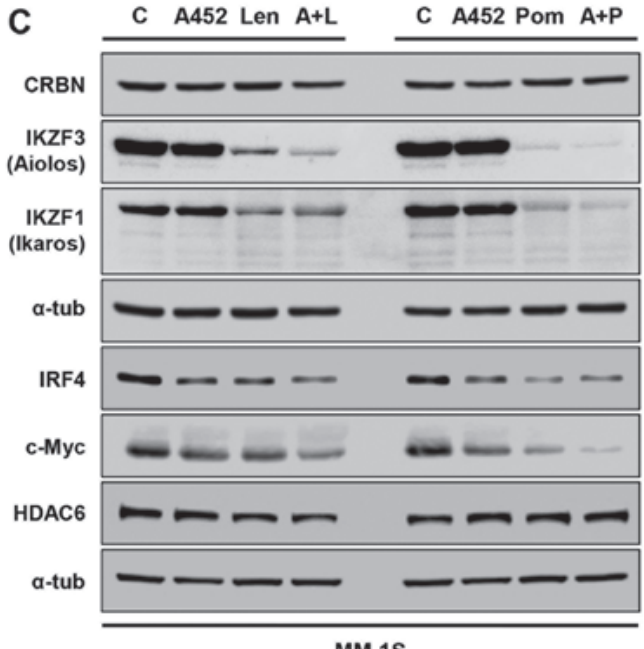

B

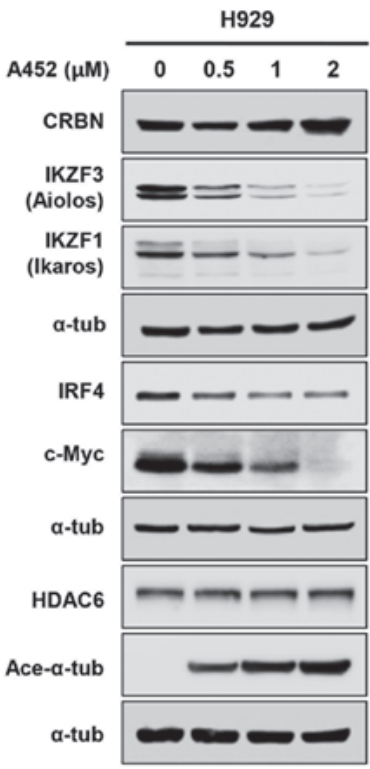

D

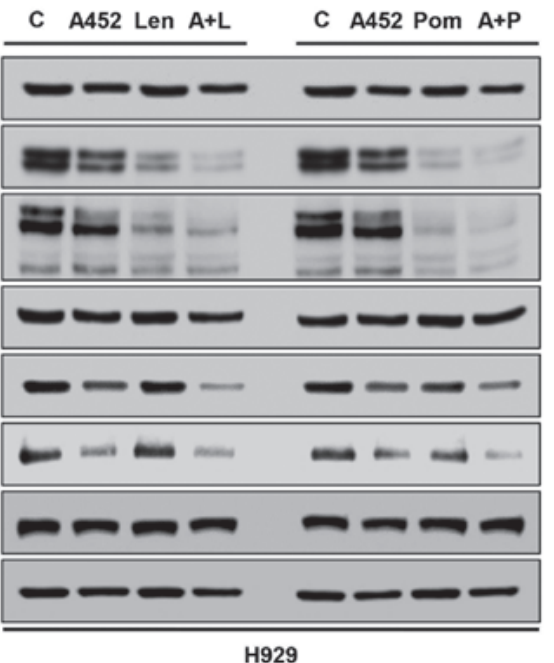

Figure 4. IMiDs in combination with A452 synergistically downregulate c-Myc, IRF4 and IKZF1/3. (A) MM.1S and (B) H929 cells were treated with $0.1 \%$ DMSO (control) or A452 at the indicated concentrations for $24 \mathrm{~h}$. (C) MM.1S and (D) H929 cells were treated with $0.1 \%$ DMSO (control), A452 (0.5 $\mu$ M), Len $(1 \mu \mathrm{M})$ or Pom $(0.25 \mu \mathrm{M})$ or in combination with these compounds, as indicated, for $24 \mathrm{~h}$. Whole-cell lysates were subjected to immunoblotting with indicated antibodies. $\alpha$-tubulin was used as a loading control. IMiDs, immunomodulatory drugs; Len, lenalidomide; Pom, pomalidomide.

Table II. Median CI for cells exposed to various drug combinations.

\begin{tabular}{lccc}
\hline Cell line Drug & $\begin{array}{c}\text { Mean } \\
\text { CI value }\end{array}$ & CI range & Synergy
\end{tabular}

\begin{tabular}{lcccl}
\hline MM.1S & A452 + Len & 0.301 & $0.168-0.383$ & Synergism \\
& A452 + Pom & 0.614 & $0.303-0.855$ & Synergism \\
& ACY + Len & 0.582 & $0.367-0.901$ & Synergism \\
& ACY + Pom & 0.634 & $0.423-0.805$ & Synergism \\
H929 & A452 + Len & 0.405 & $0.211-0.581$ & Synergism \\
& A452 + Pom & 0.645 & $0.434-0.939$ & Synergism \\
& ACY + Len & 0.138 & $0.072-0.197$ & Synergism \\
& ACY + Pom & 0.620 & $0.516-0.743$ & Synergism
\end{tabular}

Synergism, $\mathrm{CI}<0.7$; moderate synergism, $\mathrm{CI}=0.7-0.9$; additive effect, $\mathrm{CI}=0.9-1.1 . \mathrm{ACY}, \mathrm{ACY}-1215$; CI, combination index, Led, lenalidomide, Pom, pomalidomide.
A452 in combination withIMiDs synergistically downregulates the expression of $c-M y c, I R F 4$ and IKZFI/3. c-Myc and IRF4 play a pivotal role in the progression of MM, and previous studies have shown that IMiDs (41) and ACY-1215, an HDAC6 inhibitor with minimal effects on class I HDACs (33), downregulate the expression of c-Myc and IRF4 in MM cells. Therefore, in this study, the inhibitory effects of A452 on c-Myc and IRF4 expression levels were examined. A452 downregulated the expression of c-Myc and IRF4 in the MM.1S and H929 cells, in a dose-dependent manner (Fig. 4A and B). It has previously been reported that IMiDs bind to CRBN, which subsequently causes the degradation of IKZF1 and IKZF3 $(42,43)$. Furthermore, downregulation of CRBN leads to resistance to IMiD treatment $(13,44)$. Therefore, the present study examined whether A452 modulates the expression and/or function of CRBN. A452 did not alter the expression of CRBN, but downregulated the expression of IKZF1 and IKZF3 in both cell lines. 
A
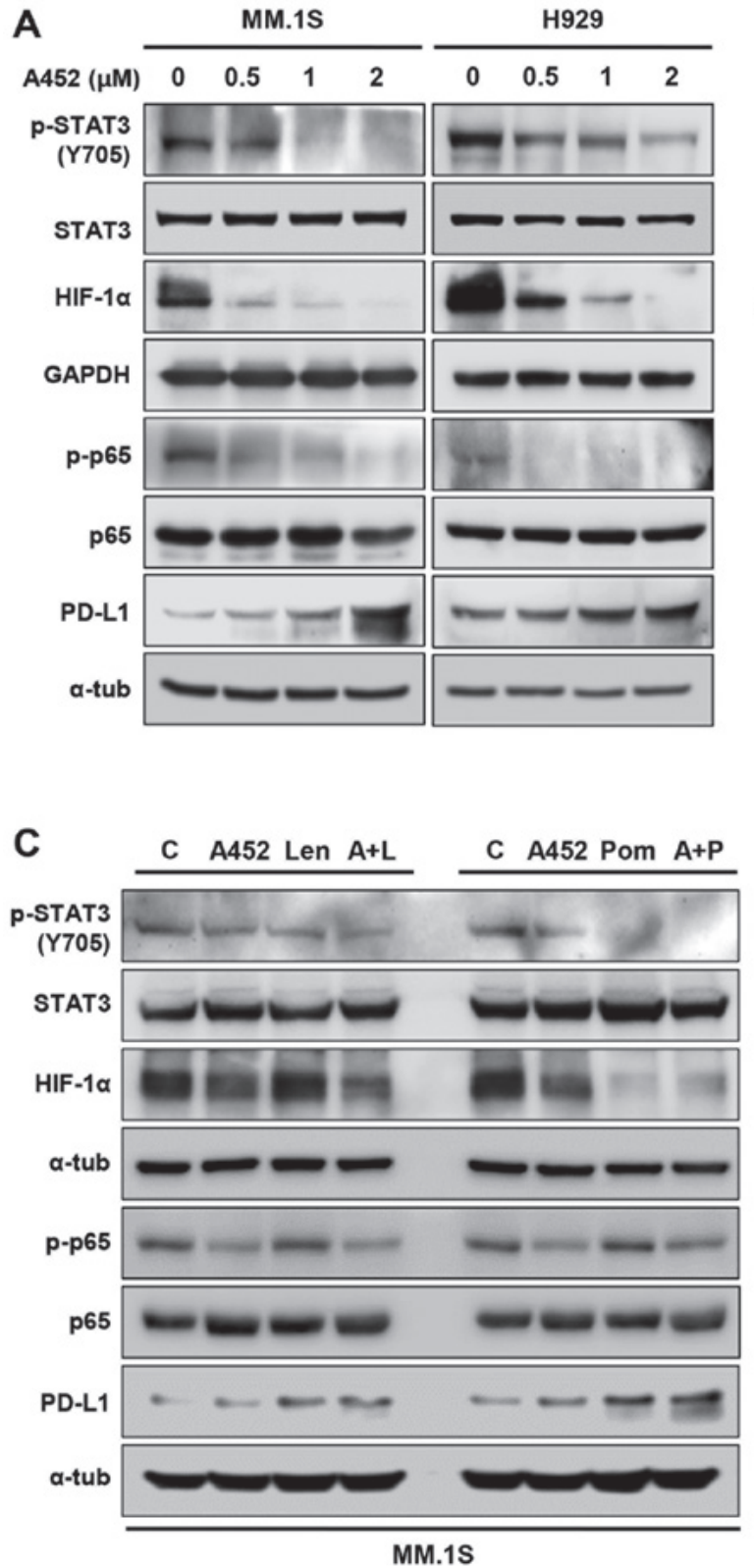

B
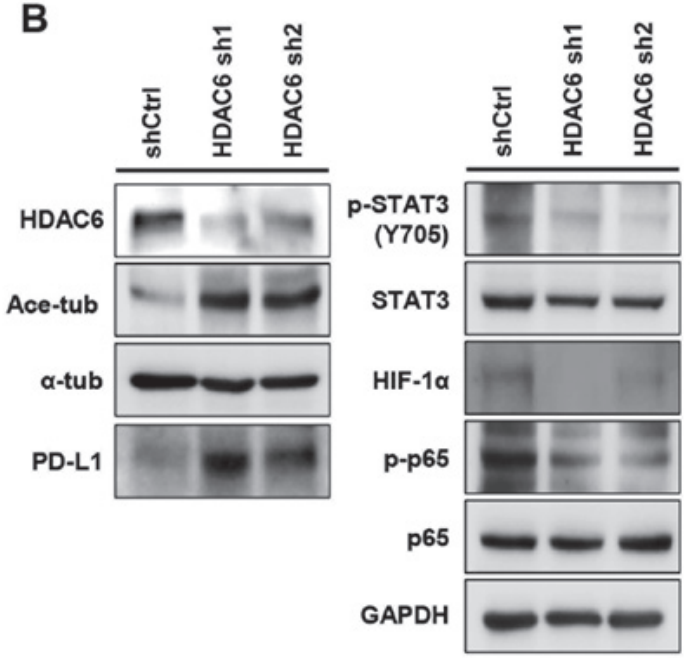

D

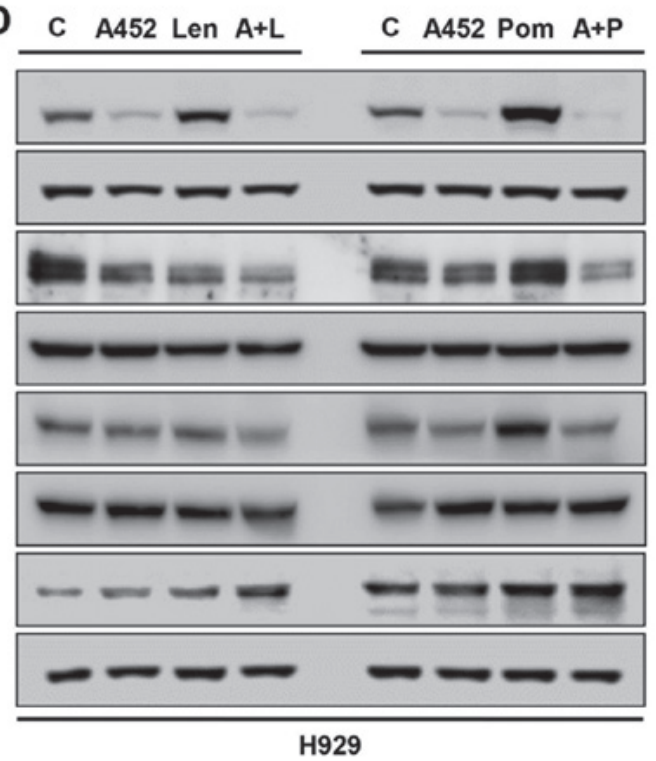

Figure 5. IMiDs in combination with A452 synergistically upregulate PD-L1. (A) MM.1S and H929 cells were treated with 0.1\% DMSO (control) or A452 at the indicated concentrations for $24 \mathrm{~h}$. (B) Stable knockdown of HDAC6 was established in MM.1S cells by expressing shRNA constructs targeting HDAC6 (HDAC6sh) or a non-target control shRNA (shCtrl NT). (C) MM.1S and (D) H929 cells were treated with 0.1\% DMSO (control), A452 (0.5 $\mu$ M), Len (1 $\mu$ M) or Pom $(0.25 \mu \mathrm{M})$ or in combination with these compounds as indicated for $24 \mathrm{~h}$. Whole-cell lysates were subjected to immunoblotting with indicated antibodies. $\alpha$-tubulin and GAPDH were used as a loading control. HDAC, histone deacetylase; IMiDs, immunomodulatory drugs.

As ACY-1215 with Len synergistically downregulate c-Myc, IRF4 and IKZF1/3 *expression in MM (33), the present study, we examined whether combination treatment with A452 and IMiDs would cause this effect. As shown in Fig. 4C and D, combined treatment with A452 and Len or Pom synergistically decreased the expression of c-Myc, IRF4 and IKZF1/3 without reducing the expression of CRBN in the MM cells compared to the control, even A452 slightly increased its level. (Figs. S4 and S5). Overall, these results indicate that combined treatment with A452 and IMiDs enhances the downregulation of c-Myc, IRF4 and IKZF1/3 in MM.

A452 controls the upregulation of PD-L1 in MM cells. A recent study demonstrated that pan-HDACis (LBH589 and PDX101) and class I HDACis (MS275 and MGCD0103) upregulated PD-L1 via the STAT3 pathway in melanoma, whereas HDAC6i ACY-1215 and Nexturastat and HDAC8i PCI34051 did not alter the expression of PD-L1 (45). In addition, transcription factors, such as STAT3, HIF-1 $\alpha$ and NF-kB have been found to regulate PD-L1 transcriptionally (46). Therefore, the present study examined the effect of HDAC6i on expression of PD-L1 via the modulation of transcription factors in MM cells. A452 treatment resulted in increased levels of PD-L1 in the MM cells, whereas the phosphorylation levels of STAT3 and $\mathrm{p} 65$, and the level of HIF- $1 \alpha$ decreased in the MM.1S and H929 cells (Figs. 5A and S6). Similar results were observed in other U266 MM cells (data not shown). Similar to A452 treatment, HDAC6 knockdown by shRNA (Fig. 5B) led 

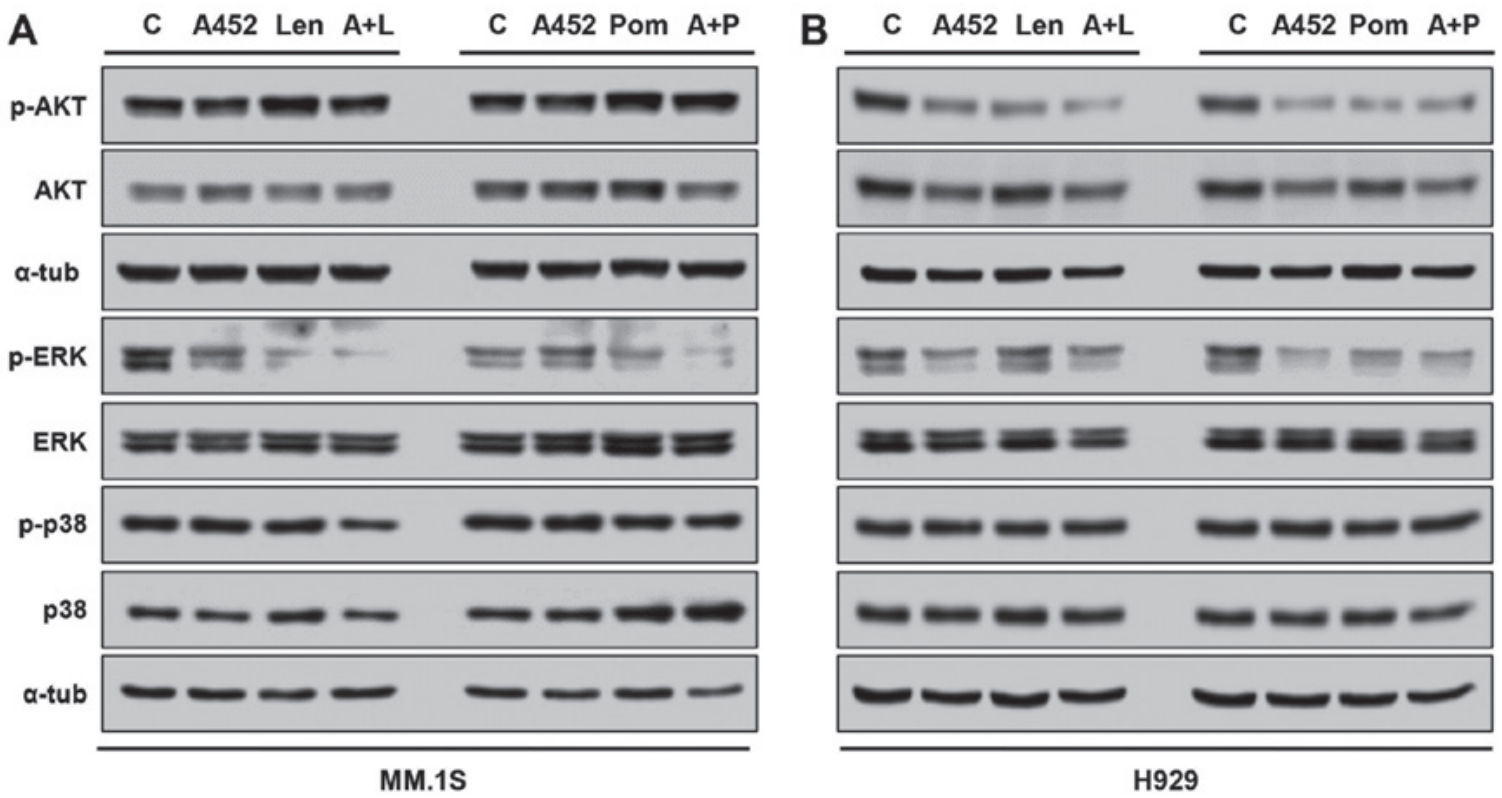

Figure 6. Co-treatment with A452 and IMiDs leads to a pronounced inhibition of AKT and ERK. (A) MM.1S and (B) H929 cells were treated with 0.1\% DMSO (control) or A452 $(0.5 \mu \mathrm{M})$, Len $(1 \mu \mathrm{M})$ or Pom $(0.25 \mu \mathrm{M})$ or in combination with these compounds as indicated for $24 \mathrm{~h}$. Whole-cell lysates were subjected to immunoblotting with indicated antibodies. $\alpha$-tubulin was used as a loading control. IMiDs, immunomodulatory drugs; Len, lenalidomide; Pom, pomalidomide.

to similar effects, suggesting that this effect was due to the inhibition of HDAC6. In addition, combination treatment with A452 and IMiDs slightly enhanced the induction of PD-L1 in both MM cell lines (Figs. 5C and D and S6). Similar results were also observed in other U266 MM cells (data not shown). However, ACY-1215 did not upregulate PD-L1 expression (Fig. S7). Thus, these results indicate that HDAC6 regulates the expression level of PD-L1 irrespective of its known transcription factors.

ERK and AKT inactivation plays functional roles in the synergistic effects of $A 452$ and IMiDs. To further address the synergism at the molecular level, several signaling pathways were evaluated in the MM.1S and H929 MM cells. As shown in Fig. 6, within 24 h, both HDAC6i and IMiDs modulated either AKT or ERK. A452 induced a decrease in ERK-MAPK phosphorylation and AKT activation in both MM cells compared with the untreated cells. The combination of A452 with Len or Pom synergistically decreased the phosphorylation of ERK in both cells and the phosphorylation of AKT in the H929 cells, compared with each compound alone (Fig. S8). By contrast, p38-MAPK activation remained relatively unaltered (although some significant differences were observed) in both MM cells. Although less evident, similar results were observed in the MM.1S cells. Therefore, these results indicate that combined treatment with A452 and IMiDs leads to the suppression of cytoprotective ERK and AKT.

A452 enhances the cytotoxicity induced by IMiDs with bortezomib or dexamethasone. As Len together with Dex is a standard treatment regimen for MM, in the present study, we then examined whether A452 enhances the cytotoxicity triggered by this drug treatment. A452 enhanced the decrease in MM cell viability induced by Len or Pom with Dex in both the Dex-sensitive MM.1S and Dex-resistant H929 cells
(Fig. 7A and B). The results of western blot analysis clearly revealed that A452 downregulated c-Myc expression, and upregulated the cleavage of caspase- 3 and PARP, in a dose-dependent manner (Figs. 7C and D, S9 and S10). The combination of Len and BTZ is another standard treatment option for MM. Other studies have shown that treatment with the HDAC6 inhibitor, ACY-1215, or tubacin with BTZ or carfilzomib exerts synergistic MM cytotoxicity, associated with endoplasmic reticulum stress due to the accumulation of polyubiquitinated proteins $(31,47,48)$. Therefore, the present study also examined whether A452 enhances the cytotoxicity induced by Len or Pom with BTZ. A452 enhanced the inhibition of viability induced by Len with BTZ in a dose-dependent manner (Fig. 7E and F). Similar results were obtained in the MM.1S and H929 cells treated with A452 and BTZ with Pom (Fig. 8). Taken together, these results indicate that A452 enhances the MM cytotoxicity triggered by standard MM treatment options that include Len/Pom and/or BTZ or Dex, and abrogates the resistance conferred by Dex-acquired resistance.

\section{Discussion}

Despite progress due to the development of IMiDs and proteasome inhibitors which have significantly extended patient overall survival rates, MM remains incurable and eventually leads to death (1). Therefore, novel drugs and/or combination treatment strategies are required to further improve MM patient survival rates. The results of the present study indicated that the novel HDAC6-selective inhibitor, A452, interacted synergistically with the IMIDs, Len or Pom, to induce cell death in MM, including that of Dex-resistant cells. These studies were prompted by several considerations. First, the HDAC6-selective inhibitor may limit adverse effects associated with pan-HDACi and improve efficacy. Second, the HDAC6-selective inhibitor may enhance the antitumor activity 

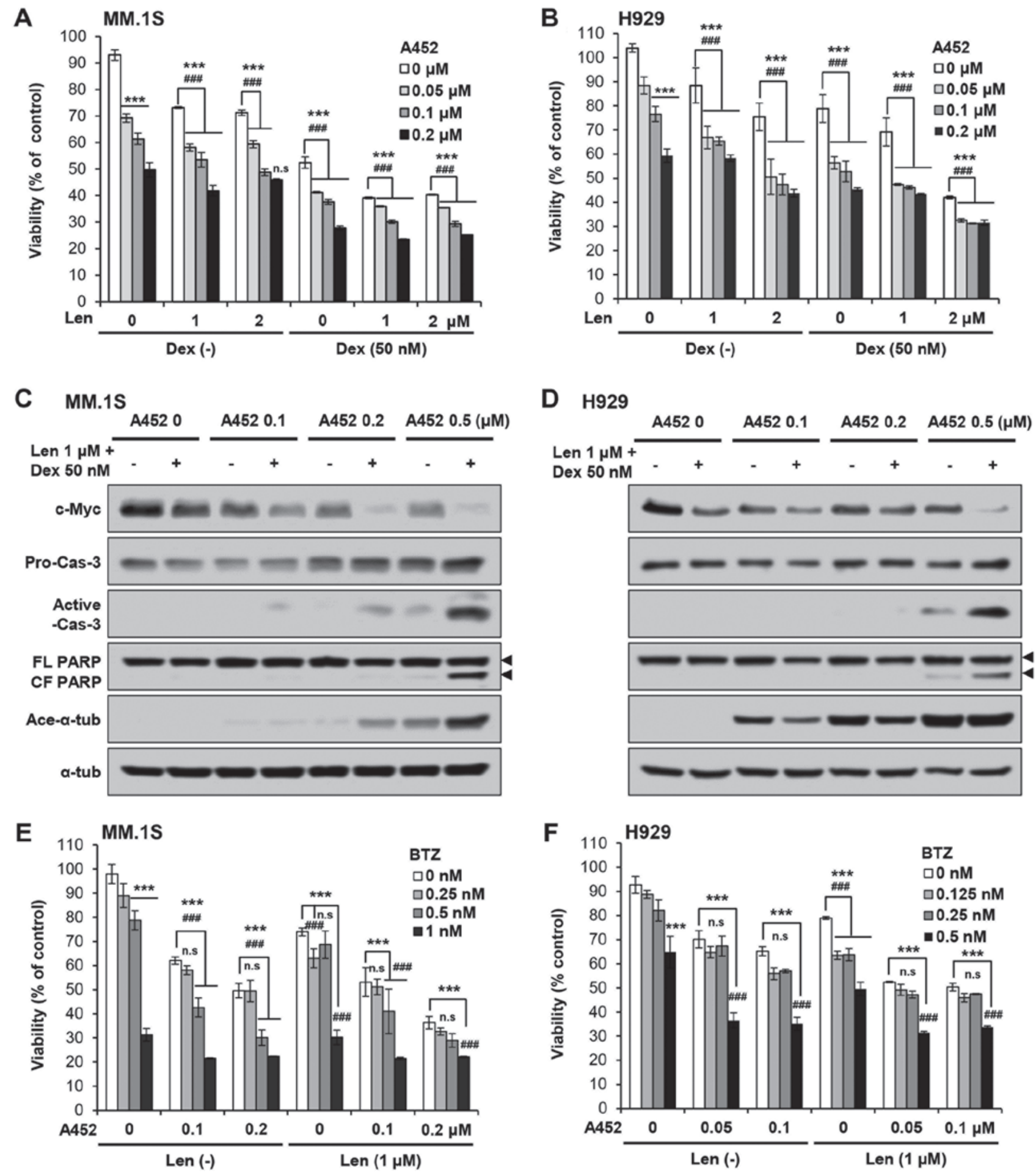

Figure 7. Len with A452 in combination with Dex or BTZ induces significant cytotoxicity. (A) MM.1S and (B) H929 cells were cultured for $48 \mathrm{~h}$ with Len $(1$ and $2 \mu \mathrm{M})$ and $\mathrm{A} 452(0.05-0.2 \mu \mathrm{M})$ in the absence or presence of Dex $(50 \mathrm{nM})$. Cell viability was measured using a CCK-8 assay. Cell counts were indirectly estimated from a standard curve generated using solutions of known cell counts. Absorbance was normalized to that of the negative control at each time interval. Data are expressed as the means \pm standard deviation from 3 independent experiments. (C) MM.1S and (D) H929 cells were cultured for $24 \mathrm{~h}$ with Len $(1 \mu \mathrm{M})$ and A452 (0.1-0.5 $\mu \mathrm{M})$ in the absence or presence of Dex $(50 \mathrm{nM})$. Whole-cell lysates were subjected to immunoblotting with indicated antibodies. $\alpha$-tubulin was used as a loading control. (E) MM.1S and (F) H929 cells were cultured for $48 \mathrm{~h}$ with Len $(1 \mu \mathrm{M})$ and A452 $(0.05-0.2 \mu \mathrm{M})$ in the absence or presence of BTZ (0.125-1 nM). Cell viability was assessed using a CCK- 8 assay. ${ }^{* * * *} \mathrm{P}<0.001$, vs. the DMSO control; ${ }^{\# \# \# ~} \mathrm{P}<0.001$, vs. the single agent- or double agents-treated groups (analysis of variance); n.s, not significant. Len, lenalidomide; Pom, pomalidomide; Dex, dexamethasone; BTZ, bortezomib.

of IMiDs in MM. Third, the HDAC6-selective inhibitor may overcome resistance to other drugs.

Synergistic interactions between HDAC6i ricolinostat and IMiDs in MM cells have been reported (33). The mechanisms underlying these interactions are multifactorial; for example, the inhibition of both proteasomal and aggresomal protein degradation and downregulation of IKZF1/3, c-Myc, and IRF4 by IMiDs, which may function together with HDAC inhibition 
A

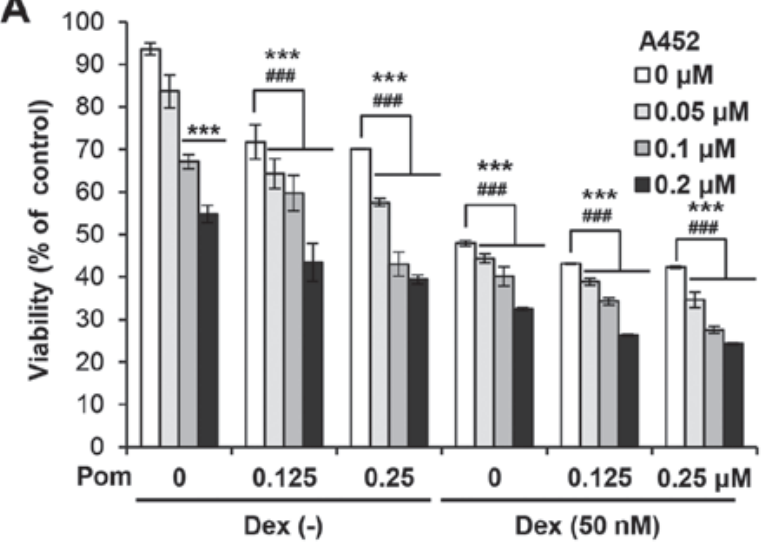

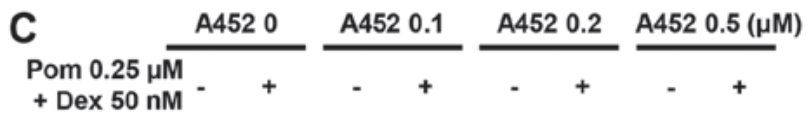

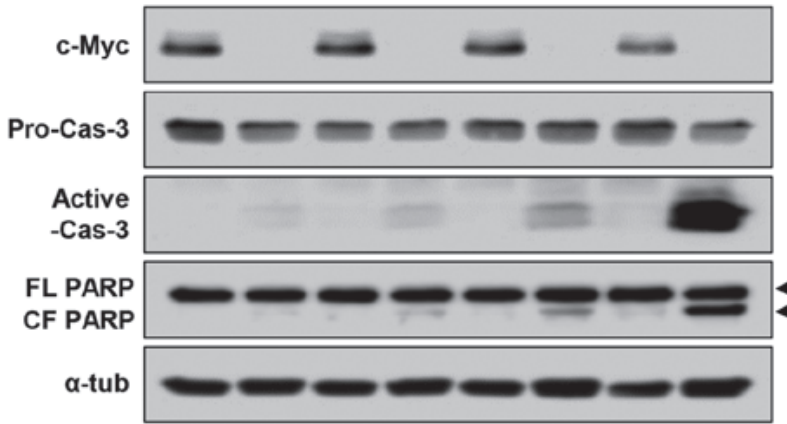

$\mathbf{E}$

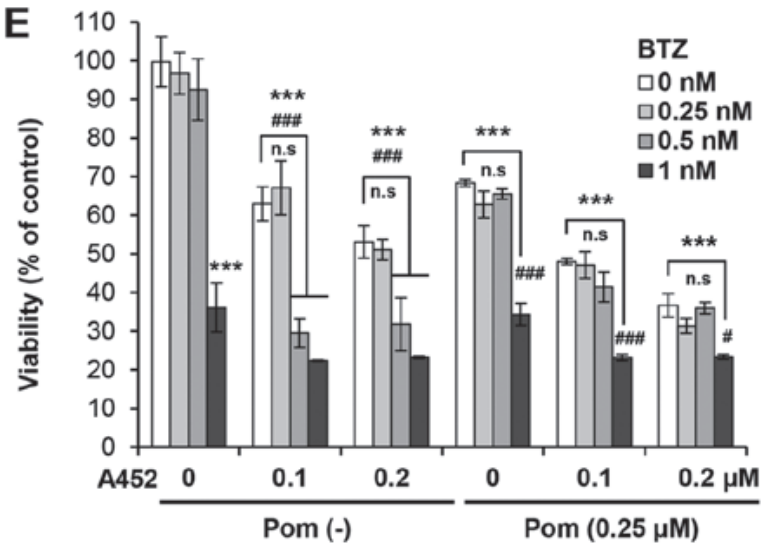

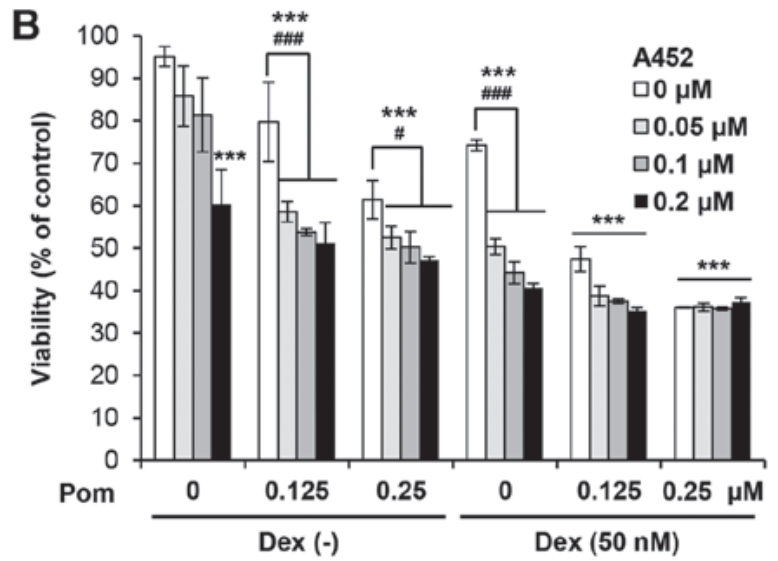
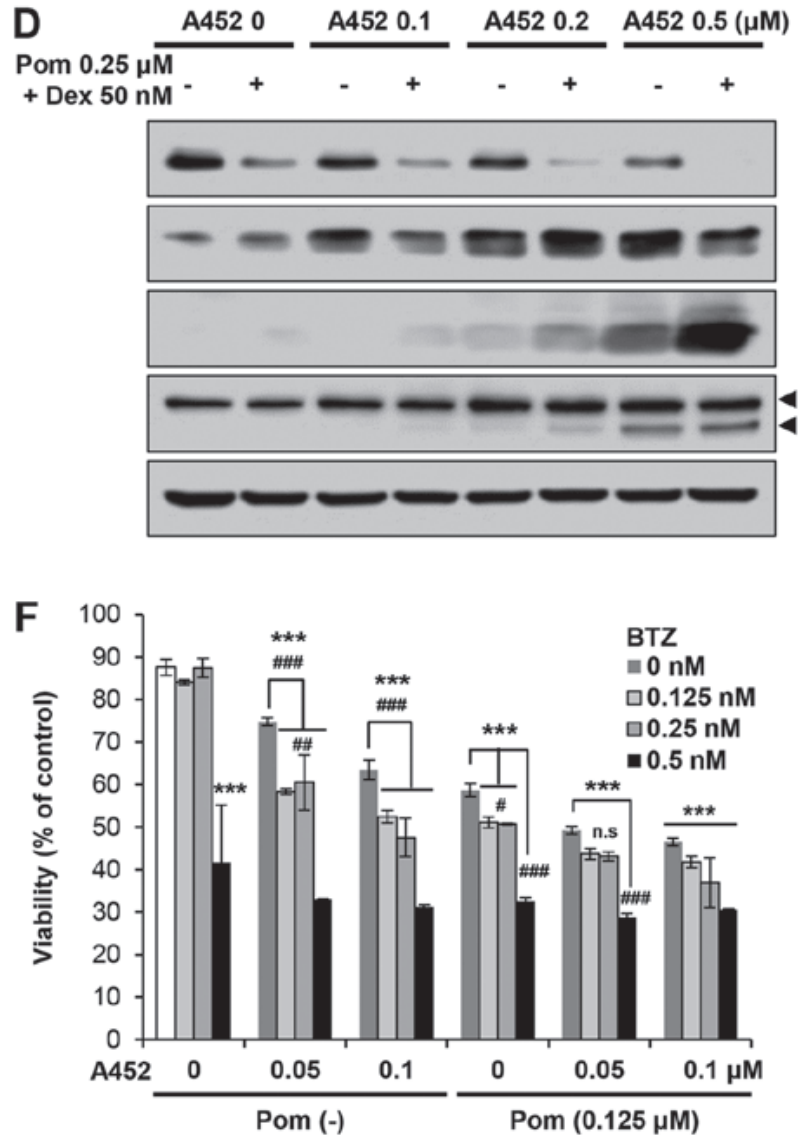

Figure 8. Pom with A452 in combination with Dex or BTZ induces significant cytotoxicity. (A) MM.1S and (B) H929 cells were cultured for 48 h with Pom $(0.125$ and $0.25 \mu \mathrm{M})$ and $\mathrm{A} 452(0.05-0.2 \mu \mathrm{M})$ in the absence or presence of Dex $(50 \mathrm{nM})$. Cell growth and viability was assessed using a CCK-8 assay. Cell counts were indirectly estimated from a standard curve generated using solutions of known cell counters. Absorbance was normalized to that of the negative control at each time interval. Data are expressed as the means \pm standard deviation from 3 independent experiments. (C) MM.1S and (D) H929 cells were cultured for $24 \mathrm{~h}$ with Pom $(0.25 \mu \mathrm{M})$ and A452 (0.1-0.5 $\mu \mathrm{M})$ in the absence or presence of Dex (50 nM). Whole-cell lysates were subjected to immunoblotting with the indicated antibodies. $\alpha$-tubulin was used as a loading control. (E) MM.1S and (F) H929 cells were cultured for $48 \mathrm{~h}$ with Pom $(0.125$ and $0.25 \mu \mathrm{M})$ and A452 $(0.05-0.2 \mu \mathrm{M})$ in the absence or presence of BTZ $(0.125-1 \mathrm{nM})$. Cell viability was assessed using a CCK-8 assay. ${ }^{* * *} \mathrm{P}<0.001$, vs. the DMSO control; ${ }^{\#} \mathrm{P}<0.05$, ${ }^{\# \#} \mathrm{P}<0.01$ and ${ }^{\# \# \#} \mathrm{P}<0.001$, vs. the single agent or double agents-treated groups (analysis of variance); n.s, not significant. Len, lenalidomide; Pom, pomalidomide; Dex, dexamethasone; BTZ, bortezomib.

to increase the expression of differentiation and cell death related genes. Consistent with previous studies, A452 significantly downregulated the expression of IKZF1/3, c-Myc and IRF4 in MM cells. Furthermore, A452 synergistically enhanced the cytotoxicity of Len or Pom in MM by downregulating the expression of IKZF1/3, c-Myc and IRF4, and by inhibiting the cytoprotective AKT and ERK pathways. It was further demonstrated that A452 with Len or Pom exerted synergistic cytotoxicity associated with the induction of caspase- 9 and caspase- 8 cleavage, activating the extrinsic and intrinsic apoptotic pathways. XIAP plays a pivotal role in MM cell survival by inhibiting apoptosis (49). In the present study, Len or Pom with A452 markedly decreased the expression of Bcl-xL and XIAP. These findings indicate that combination treatment 
enhances MM cytotoxicity by activating apoptotic signaling and inhibiting anti-apoptotic protein expression.

The results of the present study demonstrated that IMiDs with HDAC6i induced synergistic cytotoxicity in MM without reducing the level of CRBN compared to the control. The E3 ligase protein CRBN has been identified as a direct molecular target for the teratogenecity of thalidomide (12). Thalidomide and its analogs, Len and Pom, block the autoubiquitination of CRBN (13). The CRBN-dependent ubiquitination and proteasomal degradation of IKZF1 and IKZF3 sequentially leads to the downregulation of c-Myc followed by IRF4, thereby resulting in growth inhibition and apoptosis induction $(43,44,50)$. Therefore, high CRBN concentrations in $\mathrm{MM}$ are associated with an increased responsiveness to IMiDs $(51,52)$. However, pan-HDACi is able to downregulate CRBN and to antagonize Len (33). By contrast, more HDAC6-selective HDACis with weak class I HDAC inhibitory activity of ACY-1215 or A452 do not downregulate CRBN, thereby resulting in synergistic MM cytotoxicity. Importantly, A452 synergistically enhances the reduced expression of IKZF1/3, c-Myc and IRF4 induced by Len or Pom. Therefore, the selection of HDAC6i and treatment schedules should be optimized to augment cytotoxicity without reducing the expression of CRBN. Although the underlying mechanisms are unknown, it is possible that HDAC6 may be associated with $\mathrm{CRBN}$ and modulates its acetylation and ubiquitination, leading to prevention of its autoubiqutination and degradation. Therefore, further investigations are required to determine the molecular mechanisms through which HDAC6 regulates CRBN.

Triple combination therapy for MM is a common treatment regimen. For instance, RVD [(Revlimid (Len) + Velcade $(\mathrm{BTZ})+\mathrm{Dex})]$ is a one of the most effective combination treatment strategies for R/R MM (53), newly diagnosed MM (54), and maintenance therapy in MM (55). Therefore, the present study further investigated the combination treatment of Dex and Len or Pom with or without A452, and observed that A452 further enhanced cytotoxicity and apoptosis. Ricolinostat has been examined as single agent or in combination with BTZ and Dex in R/R MM in a phase I/II clinical trial $(35,56)$. Ricolinostat is also currently being investigated in a phase Ib trial in combination with Len and Dex (34). As expected, BTZ significantly enhanced the cytotoxicity triggered by Len- or Pom-Dex-A452 combination treatment. Taken together, the results of the present study indicated that A452 may enhance the anti-MM activities of Len or Pom in combination BTZ or Dex, providing a preclinical rationale for RVD + A452 clinical trials to further improve patient outcomes. Further studies are warranted to confirm our findings in patients with MM.

In conclusion, the results of the present study demonstrate that IMiDs with HDAC6-selective inhibitor induce synergistic cytotoxicity in $\mathrm{MM}$, associated with the downregulation of IKZF1/3, c-Myc, and IRF4 without the reducing CRBN expression compared to the control. By contrast, as previously demonstrated A452 at a concentration of up to $2 \mu \mathrm{M}$ does not inhibit growth and decrease the cell viability of normal fetal colon epithelial (FHC), foreskin fibroblast (BJ) and human dermal fibroblasts (HDF) cells (37). In addition, in a previous study, ACY-1215 and tubastatin A added at day 0 of culture at a concentration of up to $1 \mu \mathrm{M}$ did not alter the total number of viable megakaryocytes, which are highly specialized bone marrow cells that give rise to anucleate blood cells known as platelets. At $\leq 1 \mu \mathrm{M}$, neither HDAC6 inhibitors induced cell death by apoptosis. Only higher doses $(2-5 \mu \mathrm{M})$ inhibited cell viability (57). Consistent with previous results, in this study, at $\leq 1 \mu \mathrm{M}, \mathrm{A} 452$ and ACY-1215 did not alter the total number of viable BM-MSCs, whereas only higher doses $(\sim 2 \mu \mathrm{M})$ inhibited cell viability (data not shown). Although the present study did not investigate the cytotoxicity of HDAC6-selective inhibitors on normal plasma cells, these findings suggest that combination treatment with HDAC6i and IMiDs induce cell death in MM but not normal cells such as BM-MSCs. The data show that enhanced cell death is associated with the inactivation of AKT and ERK1/2. Furthermore, the combined treatment of HDAC6i and IMiD controlled the expression level of PD-L1 in MM cells irrespective of its known transcription factors, suggesting that HDAC6 may serve an important role in immune-related pathways. A recent clinical study of anti-PD-L1 antibodies revealed a better response rate in patients with MM with higher PD-L1 levels and progression free survival rates was weakly correlated with PD-1 levels on lymphocytes (58). Therefore, these findings support that the ability of A452 to increase the expression of PD-L1 and suggest that it may be of therapeutic benefit in immunotherapy using PD-L1 antibodies. Finally, the data obtained in the present study reveal that combined treatment of HDAC6i and IMiD is effective in Dex-resistant MM cells. Taken together, the results of this study suggest that rational combinations of IMiD with a targeted inhibitor for HDAC6 may provide beneficial therapeutic opportunities for patients with MM exhibiting resistance to conventional drugs

\section{Acknowledgements}

The authors would like to thank Dr Gyoonhee Han (Yonsei University) for providing A452.

\section{Funding}

This study was supported by the Basic Science Research Program through the National Research Foundation of Korea (NRF) funded by the Ministry of Education, Science and Technology (2016R1D1A1A02937071 and 2018R1A6A1A03023718).

\section{Availability of data and materials}

All data generated or analyzed during this study are included in this published article.

\section{Authors' contributions}

HRW, DHL and SKY designed and performed experiments, as well as analyzed the data. HWR and GWK performed the experiments and analyzed the data. SHK conceived the general design of the study, participated in the development of the approaches, wrote the initial draft of the manuscript, extensively edited the manuscript and supervised the work. All authors have read and approved the final manuscript 


\section{Ethics approval and consent to participate}

Not applicable.

\section{Patient consent for publication}

Not applicable.

\section{Competing interests}

The authors declare that they have no competing interests.

\section{References}

1. Palumbo A and Anderson K: Multiple myeloma. N Engl J Med 364: 1046-1060, 2011

2. Morgan GJ, Walker BA and Davies FE: The genetic architecture of multiple myeloma. Nat Rev Cancer 12: 335-348, 2012.

3. Offidani M, Corvatta L, Caraffa P, Leoni P, Pautasso C, Larocca A and Palumbo A: Pomalidomide for the treatment of relapsed-refractory multiple myeloma: A review of biological and clinical data. Expert Rev Anticancer Ther 14: 499-510, 2014

4. Moehler T and Goldschmidt $\mathrm{H}$ : Therapy of relapsed and refractory multiple myeloma. Recent Results Cancer Res 183: 239-271, 2011

5. Laubach JP, Mitsiades CS, Mahindra A, Luskin MR, Rosenblatt J, Ghobrial IM, Schlossman RL, Avigan D, Raje N, MunshiNC, et al: Management of relapsed and relapsed/refractory multiple myeloma. J Natl Compr Canc Netw 9: 1209-1216, 2011.

6. Lonial S, Mitsiades CS and Richardson PG: Treatment options for relapsed and refractory multiple myeloma. Clin Cancer Res 17: 1264-1277, 2011.

7. Dredge K, Horsfall R, Robinson SP, Zhang LH, Lu L, Tang Y, Shirley MA, Muller G, Schafer P, Stirling D, et al: Orally administered lenalidomide (CC-5013) is anti-angiogenic in vivo and inhibits endothelial cell migration and Akt phosphorylation in vitro. Microvasc Res 69: 56-63, 2005.

8. Davies FE, Raje N, Hideshima T, Lentzsch S, Young G, Tai YT, Lin B, Podar K, Gupta D, Chauhan D, et al: Thalidomide and immunomodulatory derivatives augment natural killer cell cytotoxicity in multiple myeloma. Blood 98: 210-216, 2001.

9. Dredge K, Marriott JB, Macdonald CD, Man HW, Chen R, Muller GW, Stirling D and Dalgleish AG: Novel thalidomide analogues display anti-angiogenic activity independently of immunomodulatory effects. Br J Cancer 87: 1166-1172, 2002.

10. Reddy N, Hernandez-Ilizaliturri FJ, Deeb G, Roth M, Vaughn M, Knight J, Wallace P and Czuczman MS: Immunomodulatory drugs stimulate natural killer-cell function, alter cytokine production by dendritic cells, and inhibit angiogenesis enhancing the anti-tumour activity of rituximab in vivo. Br J Haematol 140: 36-45, 2008.

11. Verhelle D, Corral LG, Wong K, Mueller JH, Moutouh-de Parseval L, Jensen-Pergakes K, Schafer PH, Chen R, Glezer E, Ferguson GD, et al: Lenalidomide and CC-4047 inhibit the proliferation of malignant $\mathrm{B}$ cells while expanding normal CD34+ progenitor cells. Cancer Res 67: 746-755, 2007.

12. Ito T, Ando H, Suzuki T, Ogura T, Hotta K, Imamura Y, Yamaguchi $\mathrm{Y}$ and Handa $\mathrm{H}$ : Identification of a primary target of thalidomide teratogenicity. Science 327: 1345-1350, 2010

13. Lopez-Girona A, Mendy D, Ito T, Miller K, Gandhi AK, Kang J, Karasawa S, Carmel G, Jackson P, Abbasian M, et al Cereblon is a direct protein target for immunomodulatory and antiproliferative activities of lenalidomide and pomalidomide. Leukemia 26: 2326-2335, 2012.

14. Aldana-Masangkay GI, Rodriguez-Gonzalez A, Lin T, Ikeda AK, Hsieh YT, Kim YM, Lomenick B, Okemoto K Landaw EM, Wang D, et al: Tubacin suppresses proliferation and induces apoptosis of acute lymphoblastic leukemia cells. Leuk Lymphoma 52: 1544-1555, 2011.

15. Fecteau JF, Corral LG, GhiaEM, Gaidarova S, Futalan D, Bharati IS, Cathers B, Schwaederlé M, Cui B, Lopez-Girona A, et al: Lenalidomide inhibits the proliferation of CLL cells via a cereblon/p21(WAF1/Cip1)-dependent mechanism independent of functional p53. Blood 124: 1637-1644, 2014.

16. Schey S and Ramasamy K: Pomalidomide therapy for myeloma. Expert Opin Investig Drugs 20: 691-700, 2011.
17. Mehnert JM and Kelly WK: Histone deacetylase inhibitors: Biology and mechanism of action. Cancer J 13: 23-29, 2007.

18. Richon VM, Garcia-Vargas J and Hardwick JS: Development of vorinostat: Current applications and future perspectives for cancer therapy. Cancer Lett 280: 201-210, 2009.

19. Ropero S and Esteller M: The role of histone deacetylases (HDACs) in human cancer. Mol Oncol 1: 19-25, 2007.

20. Xu WS, Parmigiani RB and Marks PA: Histone deacetylase inhibitors: Molecular mechanisms of action. Oncogene 26: 5541-5552, 2007

21. Campas-Moya C: Romidepsin for the treatment of cutaneous T-cell lymphoma. Drugs Today (Barc) 45: 787-795, 2009.

22. Duvic M, Olsen EA, Breneman D, Pacheco TR, Parker S, Vonderheid EC, Abuav R, Ricker JL, Rizvi S, Chen C, et al: Evaluation of the long-term tolerability and clinical benefit of vorinostat in patients with advanced cutaneous T-cell lymphoma. Clin Lymphoma Myeloma 9: 412-416, 2009.

23. Marks PA and Breslow R: Dimethyl sulfoxide to vorinostat: Development of this histone deacetylase inhibitor as an anticancer drug. Nat Biotechnol 25: 84-90, 2007.

24. Siegel DS, Richardson P, Dimopoulos M, Moreau P, Mitsiades C, Weber D, Houp J, Gause C, Vuocolo S, Eid J, et al: Vorinostat in combination with lenalidomide and dexamethasone in patients with relapsed or refractory multiple myeloma. Blood Cancer J 4: e202, 2014.

25. OcioEM,VilanovaD,AtadjaP,MaisoP,CrusoeE,Fernández-LázaroD, Garayoa M, San-Segundo L, Hernández-Iglesias T, de Alava E, et al: In vitro and in vivo rationale for the triple combination of panobinostat (LBH589) and dexamethasone with either bortezomib or lenalidomide in multiple myeloma. Haematologica 95: 794-803, 2010.

26. San-Miguel JF, Richardson PG, Günther A, Sezer O, Siegel D, Bladé J, LeBlanc R, Sutherland H, Sopala M, Mishra KK, et al: Phase Ib study of panobinostat and bortezomib in relapsed or relapsed and refractory multiple myeloma. J Clin Oncol 31: 3696-3703, 2013

27. Sivaraj D, Green MM and Gasparetto C: Panobinostat for the management of multiple myeloma. Future Oncol 13: 477-488, 2017.

28. Bergman JA, Woan K,Perez-Villarroel P, Villagra A,Sotomayor EM and Kozikowski AP: Selective histone deacetylase 6 inhibitors bearing substituted urea linkers inhibit melanoma cell growth. J Med Chem 55: 9891-9899, 2012

29. Butler LM, Agus DB, Scher HI, Higgins B, Rose A, Cordon-Cardo C, Thaler HT, Rifkind RA, Marks PA and Richon VM: Suberoylanilide hydroxamic acid, an inhibitor of histone deacetylase, suppresses the growth of prostate cancer cells in vitro and in vivo. Cancer Res 60: 5165-5170, 2000.

30. Inks ES, Josey BJ, Jesinkey SR and Chou CJ: A novel class of small molecule inhibitors of HDAC6. ACS Chem Biol 7: 331-339, 2012.

31. Santo L, Hideshima T, Kung AL, Tseng JC, Tamang D, Yang M, Jarpe M, van Duzer JH, Mazitschek R, Ogier WC, et al: Preclinical activity, pharmacodynamic, and pharmacokinetic properties of a selective HDAC6 inhibitor, ACY-1215, in combination with bortezomib in multiple myeloma. Blood 119: 2579-2589, 2012.

32. Smil DV, Manku S, Chantigny YA, Leit S, Wahhab A, Yan TP, Fournel M, Maroun C, Li Z, Lemieux AM, et al: Novel HDAC6 isoform selective chiral small molecule histone deacetylase inhibitors. Bioorg Med Chem Lett 19: 688-692, 2009.

33. Hideshima T, Cottini F, Ohguchi H, Jakubikova J, Gorgun G, Mimura N, Tai YT, Munshi NC, Richardson PG and Anderson KC: Rational combination treatment with histone deacetylase inhibitors and immunomodulatory drugs in multiple myeloma. Blood Cancer J 5: e312, 2015.

34. Yee AJ, Bensinger WI, Supko JG, Voorhees PM, Berdeja JG, Richardson PG, Libby EN, Wallace EE, Birrer NE, Burke JN, et al: Ricolinostat plus lenalidomide, and dexamethasone in relapsed or refractory multiple myeloma: A multicentre phase $1 \mathrm{~b}$ trial. Lancet Oncol 17: 1569-1578, 2016.

35. Raje N, Vogl DT, Hari PN, et al: ACY-1215, a selective histone deacetylase (HDAC) 6 inhibitor: Interim results of combination therapy with bortezomib in patients with multiple myeloma (MM). Blood 122: 759, 2013.

36. Choi E, Lee C, Park JE, Seo JJ, Cho M, Kang JS, Kim HM, Park SK, Lee K and Han G: Structure and property based design, synthesis and biological evaluation of $\gamma$-lactam based HDAC inhibitors. Bioorg Med Chem Lett 21: 1218-1221, 2011. 
37. Ryu HW, Shin DH, Lee DH, Won HR and Kwon SH: A potent hydroxamic acid-based, small-molecule inhibitor A452 preferentially inhibits HDAC6 activity and induces cytotoxicity toward cancer cells irrespective of p53 status. Carcinogenesis 39: 72-83, 2018.

38. Lee DH, Won HR, Ryu HW, Han JM and Kwon SH: The HDAC6 inhibitor ACY-1215 enhances the anticancer activity of oxaliplatin in colorectal cancer cells. Int J Oncol 53: 844-854, 2018

39. Chou TC: Drug combination studies and their synergy quantification using the Chou-Talalay method. Cancer Res 70: 440-446, 2010.

40. Witter DJ, Harrington P, Wilson KJ, Chenard M, Fleming JC, Haines B, Kral AM, Secrist JP and Miller TA: Optimization of biaryl Selective HDAC1\&2 Inhibitors (SHI-1:2). Bioorg Med Chem Lett 18: 726-731, 2008.

41. López R, Cuca LE and Delgado G: Antileishmanial and immunomodulatory activity of Xylopia discreta. Parasite Immunol 31: 623-630, 2009

42. Krönke J, Udeshi ND, Narla A, Grauman P, Hurst SN McConkey M, Svinkina T, Heckl D, Comer E, Li X, et al: Lenalidomide causes selective degradation of IKZF1 and IKZF3 in multiple myeloma cells. Science 343: 301-305, 2014.

43. Lu G, Middleton RE, Sun H, Naniong M, Ott CJ, Mitsiades CS, Wong KK, Bradner JE and Kaelin WG Jr: The myeloma drug lenalidomide promotes the cereblon-dependent destruction of Ikaros proteins. Science 343: 305-309, 2014.

44. Zhu YX, Braggio E, Shi CX, Bruins LA, Schmidt JE, Van Wier S, Chang XB, Bjorklund CC, Fonseca R, Bergsagel PL, et al: Cereblon expression is required for the antimyeloma activity of lenalidomide and pomalidomide. Blood 118: 4771-4779, 2011.

45. M L, P PV, T K, M P, e S, J P, K v W, C L, F C, S D, et al: Essential role of HDAC6 in the regulation of PD-L1 in melanoma. Mol Oncol 10: 735-750, 2016.

46. Chen J, Jiang CC, Jin L and Zhang XD: Regulation of PD-L1: A novel role of pro-survival signalling in cancer. Ann Oncol 27: 409-416, 2016.

47. Hideshima T, Bradner JE, Wong J, Chauhan D, Richardson P, Schreiber SL and Anderson KC: Small-molecule inhibition of proteasome and aggresome function induces synergistic antitumor activity in multiple myeloma. Proc Natl Acad Sci USA 102: 8567-8572, 2005

48. Hideshima T, Mazitschek R, Santo L, Mimura N, Gorgun G, Richardson PG, Raje $\mathrm{N}$ and Anderson KC: Induction of differential apoptotic pathways in multiple myeloma cells by class-selective histone deacetylase inhibitors. Leukemia 28: 457-460, 2014

49. Desplanques G, Giuliani N, Delsignore R, Rizzoli V, Bataille R and Barillé-Nion S: Impact of XIAP protein levels on the survival of myeloma cells. Haematologica 94: 87-93, 2009.
50. Bjorklund CC, Lu L, Kang J, Hagner PR, Havens CG, Amatangelo M, Wang M, Ren Y, Couto S, Breider M, et al: Rate of CRL4(CRBN) substrate Ikaros and Aiolos degradation underlies differential activity of lenalidomide and pomalidomide in multiple myeloma cells by regulation of c-Myc and IRF4. Blood Cancer J 5: e354, 2015.

51. Broyl A, Kuiper R, van Duin M, van der Holt B, el Jarari L, Bertsch U, Zweegman S, Buijs A, Hose D, Lokhorst HM, et al; Dutch-Belgian HOVON group; German GMMG Group: High cereblon expression is associated with better survival in patients with newly diagnosed multiple myeloma treated with thalidomide maintenance. Blood 121: 624-627, 2013.

52. Heintel D, Rocci A, Ludwig H, Bolomsky A, Caltagirone S, Schreder M, Pfeifer S, Gisslinger H, Zojer N, Jäger U, et al: High expression of cereblon (CRBN) is associated with improved clinical response in patients with multiple myeloma treated with lenalidomide and dexamethasone. Br J Haematol 161: 695-700, 2013.

53. Richardson PG, Xie W, Jagannath S, Jakubowiak A, Lonial S, Raje NS, Alsina M, Ghobrial IM, Schlossman RL, Munshi NC, et al: A phase 2 trial of lenalidomide, bortezomib, and dexamethasone in patients with relapsed and relapsed/refractory myeloma. Blood 123: 1461-1469, 2014.

54. Richardson PG, Weller E, Lonial S, Jakubowiak AJ, Jagannath S, Raje NS, Avigan DE, Xie W, Ghobrial IM, Schlossman RL, et al: Lenalidomide, bortezomib, and dexamethasone combination therapy in patients with newly diagnosed multiple myeloma. Blood 116: 679-686, 2010.

55. Nooka AK, Kaufman JL, Muppidi S, Langston A, Heffner LT, Gleason C, Casbourne D, Saxe D, Boise LH and Lonial S: Consolidation and maintenance therapy with lenalidomide, bortezomib and dexamethasone (RVD) in high-risk myeloma patients. Leukemia 28: 690-693, 2014.

56. Ashjian E and Redic K: Multiple myeloma: Updates for pharmacists in the treatment of relapsed and refractory disease. J Oncol Pharm Pract 22: 289-302, 2016.

57. Messaoudi K, Ali A, Ishaq R, Palazzo A, Sliwa D, Bluteau O, Souquère $\mathrm{S}$, Muller D, Diop KM, Rameau $\mathrm{P}$, et al: Critical role of the HDAC6-cortactin axis in human megakaryocyte maturation leading to a proplatelet-formation defect. Nat Commun 8: 1786, 2017.

58. Badros A, Hyjek E, Ma N, Lesokhin A, Dogan A Rapoport AP, Kocoglu M, Lederer E, Philip S, Milliron T, et al: Pembrolizumab, pomalidomide, and low-dose dexamethasone for relapsed/refractory multiple myeloma. Blood 130: 1189-1197, 2017. 